IZA DP No. 8570

A Biological Basis for the Gender Wage Gap: Fecundity and Age and Educational Hypogamy

Solomon W. Polachek

Xu Zhang

Xing Zhou

October 2014 


\title{
A Biological Basis for the Gender Wage Gap: Fecundity and Age and Educational Hypogamy
}

\author{
Solomon W. Polachek \\ State University of New York at Binghamton \\ and IZA \\ Xu Zhang \\ State University of New York at Farmingdale
}

Xing Zhou

Nankai University

Discussion Paper No. 8570

October 2014

\author{
IZA \\ P.O. Box 7240 \\ 53072 Bonn \\ Germany \\ Phone: +49-228-3894-0 \\ Fax: +49-228-3894-180 \\ E-mail: iza@iza.org
}

Any opinions expressed here are those of the author(s) and not those of IZA. Research published in this series may include views on policy, but the institute itself takes no institutional policy positions. The IZA research network is committed to the IZA Guiding Principles of Research Integrity.

The Institute for the Study of Labor (IZA) in Bonn is a local and virtual international research center and a place of communication between science, politics and business. IZA is an independent nonprofit organization supported by Deutsche Post Foundation. The center is associated with the University of Bonn and offers a stimulating research environment through its international network, workshops and conferences, data service, project support, research visits and doctoral program. IZA engages in (i) original and internationally competitive research in all fields of labor economics, (ii) development of policy concepts, and (iii) dissemination of research results and concepts to the interested public.

IZA Discussion Papers often represent preliminary work and are circulated to encourage discussion. Citation of such a paper should account for its provisional character. A revised version may be available directly from the author. 


\section{ABSTRACT \\ A Biological Basis for the Gender Wage Gap: Fecundity and Age and Educational Hypogamy ${ }^{*}$}

This paper shows how a shorter fecundity horizon for females (a biological constraint) leads to age and educational disparities between husbands and wives. Empirical support is based on data from a natural experiment commencing before and ending after China's 1980 onechild law. The results indicate that fertility in China declined by about 1.2-1.4 births per woman as a result of China's anti-natalist policies. Concomitantly spousal age and educational differences narrowed by approximately 0.5-1.0 and 1.0-1.6 years respectively. These decreases in the typical husband's age and educational advantages are important in explaining the division of labor in the home, often given as a cause for the gender wage gap. Indeed, as fertility declined, which has been the historical trend in most developed countries, husband-wife age and educational differences diminished leading to less division of labor in the home and a smaller gender wage disparity. Unlike other models of division of labor in the home which rely on innately endogenous factors, this paper's theory is based on an exogenous biological constraint.

JEL Classification: J1, J2, J3, J43, J7, J8, N3, N9, O5, Y8, Z13

Keywords: gender wage gap, marital patterns, age at marriage, husband-wife age gap, husband-wife educational gap, homogamy, division of labor in the home, household economics

Corresponding author:

Solomon W. Polachek

LT 1015

Binghamton University

P.O. Box 6000

Binghamton, New York 13902

USA

E-mail: polachek@binghamton.edu

\footnotetext{
* Forthcoming in Gender Convergence in the Labor Market, Research in Labor Economics, Vol. 41. Part of this paper was written while Polachek was a visiting scholar at the NBER in Cambridge, MA. We thank Vikesh Amin, Talia Bar, Erling Barth, Fran Blau, Richard Burkhauser, Henry Farber, Dan Feenberg, Richard Freeman, Claudia Goldin, David Hacker, Larry Kahn, Subal Kumbhakar, Shelly Lundberg, Haim Ofek, Thomas Rawski, Susan Wolcott, Dennis Yang, Xi Yang, seminar participants at Cornell University, IZA, Kasetsart University (Thailand), Rutgers University, SUNY-Albany, and SUNYBuffalo, as well as Kostas Tatsiramos and two anonymous referees for valuable comments and suggestions.
} 
Then Abraham ... asked rhetorically ... shall a child be born to me, a one-hundred year old man, and to Sarah a ninety year old women? (Genesis 17:17)

\section{Introduction}

One explanation given for the gender wage gap is the division of labor in the home. According to this argument husbands specialize in market work whereas their wives specialize more in home activities. As a result, husbands work a greater portion of their lives, invest more in human capital, and attain higher wages. The relatively larger wage gap found between married men and married women (especially those with children) compared to the almost nonexistent wage gap found for single (especially never-been-married) men and women is consistent with this household division of labor hypothesis. Also consistent with this division of labor is the secularly declining wage gap coming about as fertility rates fell, divorce rates rose, and female labor force participation rates increased over the last century. These same patterns are generally observed in all countries for which there are data. However, the phenomenon social scientists still do not understand is why household division of labor occurs in the first place. This is the question addressed in this paper.

The standard reason for division of labor is comparative advantage. Comparative advantage can come about at the outset of marriage if husbands have higher wages than wives. While discrimination is one explanation why husbands earn more than their wives, another explanation might very well be the mating process - how men and women meet and marry - and the resulting differences in demographic characteristics each spouse brings to the marriage. One of these demographic differences between spouses is age. As the biblical quote above indicates, husbands are typically older than their wives. Another is educational background. Again, at least in the past, husbands' years of schooling exceeded their wives'. These husbands' age and educational advantages translates to husband-wife wage disparities which could lead to division of labor, even in the absence of discrimination. Thus the study of 
husband-wife age and educational differences is important.

Social scientists use the singulate mean age at marriage (SMAM) to compute the average age individuals marry. The SMAM data reported in the United Nations World Marriage Patterns (2000) based on 236 countries indicate husbands are older than their wives in all but one country. ${ }^{1}$ This husband-wife age gap tends to be larger in developing countries especially African nations, while in developed countries it tends to be smaller. In the US, husbands are just over 2 years older than their wives and at least in the 1960s were almost $1 / 2$ year more educated (Polachek, 1975). As a result of these age and educational advantages, husbands potentially earn more than their wives from the outset of their marriages. These earnings differences widen throughout the marriage as comparative advantage causes husbands to specialize in market activities, whereas wives tend to specialize more in home production (Polachek, 1975; Becker, 1985). Further these husband-wife wage differences are exacerbated with increased family size (Harkness and Waldfogel, 2003, and Bertrand, Goldin and Katz, 2009). ${ }^{2}$ Understanding why most men marry younger less educated women than themselves, and correspondingly why women often marry older more educated men, should shed light on the division of labor, and hence help explain the gender (and family) wage gap so prevalent in the US and other countries.

In a series of papers beginning in 1973, Gary Becker developed an economics approach to the mating process. Given the usual principles of families maximizing household utility, he showed how couples positively sort based on complementary traits and negatively sort based on substitutes. Using this approach and taking into account the biological constraint that women are fecund for shorter time durations than men, Frank Vella and Sean Collins (1990) as well as Aloysius Siow (1998) argued that fecund women are relatively scarce. As a result, they demonstrated that

\footnotetext{
${ }^{1}$ www.un.org/esa/population/publications/worldmarriage/worldmarriage.htm

${ }^{2}$ Bertrand, Goldin and Katz (2009) find that MBA mothers, especially those with well-off spouses slow down following their first birth, with concomitant deleterious effects on their subsequent wages.
} 
the average age at first marriage is lower for women than men. By employing a two-sided search model Eugenio Giolito (2003) proved that the husband-wife age gap is larger the larger the difference in fecundity horizons. Our paper builds on this literature. We adopt a two-sided matching model along with the biological fact that men have a longer fecundity horizon than women. In addition, we assume that schooling is so time and effort intensive that those in school put off having children. Our model shows (1) that husband-wife age gaps are smaller the lower the demand for children, and (2) that husband-wife schooling differences are smaller the lower the demand for children.

We test our model using data from a natural experiment occurring in China. Before 1970, China had an explicit pro-natalist policy. Between 1970 and 1980 government sentiment abruptly changed to anti-natalist, but the change was not mandated by law. The well-known "one-child law" followed in 1980. Chinese data indicate fertility decreased by over 1.4 children per family, husband-wife age differences declined by as much as 1.2 years, and the husband-wife education gap decreased by about 1.4 years from before to after China instigated its one-child policy. Further, the Chinese policy affected rural areas more than urban areas. Whereas urban fertility declined by 1.16 children, rural fertility declined by 1.5 children. Similarly the spousal age and educational gap narrowed more in rural than urban areas.

This paper differs from others in at least several ways. First, it models age and educational differences between spouses, whereas others do not. Second, it is based on exogenous biological constraints whereas others (Chiappori, Iyigun and Weiss, 2008, 2010) rely on higher female rates of return to schooling (a debatable assumption $^{3}$ and a technology where women are more productive in the home than men (an unverified assumption). Third, it makes use of a natural experiment based on

\footnotetext{
${ }^{3}$ For example, see Devereux and Hart (2008), DiPrete and Buchmann, 2006; Munich, Svejnar, and Terrell, 2005); and Hubbard (2011).
} 
China's one-child policy. ${ }^{4}$ In addition, our results reinforce important work on the demographic transition by Soares and Falcão (2008) by getting at the underlying biological mechanism which motivates the demographic transition causing the sexual division of labor.

At this point, it might be worth mentioning that our results are consistent with long-term secular declines in the husband-wife marital age gap which we explain by the more or less consistent decline in fertility. On the other hand, current theories of marriage that explain the 1970-2000 increases in marriage age based on declining fertility are hard pressed to show how overall long-term declines in fertility explain cyclical changes in the age at first marriage exhibited over the last several centuries.

The rest of the paper is organized as follows. Section 2 is a brief literature review about the theory of marriage. A two-period model in which males and females search for potential partners based on women having shorter fecundity horizons than men is introduced in section 3. Section 4 presents some stylized facts. Section 5 empirically tests the predictions using changes in husband and wife age and educational differences resulting from China's policy changes as a natural experiment. Section 6 concludes.

\section{Literature Review}

An equilibrium search model is a useful tool to analyze how a union between two entities forms. Search models can apply to the job market where potential employers and perspective job applicants are looking for particular job matches, and it can apply to consumer markets where buyers and sellers try to match with each other to

\footnotetext{
${ }^{4}$ Though not explored analytically in this paper, we should note that worldwide countries with higher infant mortality rates and higher fertility, such as the African nations, have husband-wife age gaps about five years bigger than in Western countries (United Nations World Marriage Patterns, 2000). Similarly, wives in African countries have about a year less schooling than husbands compared to wives in Western countries. (http://earthtrends.wri.org/searchable_db/results.php?years=all\&variable_ID $=1117 \&$ theme $=4 \&$ country_ID=all\&co untry_classification_ID=all).
} 
exchange specific commodities. In the marriage market, search can be used to determine who marries whom. The development of the equilibrium search model started with one-sided search. One-sided search examines how one participant determines whether to form a union from a pool of available potential partners. In these one-sided search models, one party was considered to be a passive receiver in the decision regarding who matches with whom. Gary Becker's theory is usually taken to consider a woman who tries to select a partner from a pool of marriageable men by comparing the potential utility gained from matching compared to one's current utility. The one-sided search model ignores the bilateral nature of matching, therefore now two-sided search models are more prevalent (i.e. Gale and Shapley (1962), Mortensen (1988), Burdett and Wright (1998)). Marriage is a process where women and men simultaneously search for partners and make a decision by comparing gains from marriage with their current utility.

The theory of marriage as developed by Becker $(1973,1991)$ implies several sources of gains from marriage. First, it is assumed that men have a comparative advantage in the labor market while women have a comparative advantage in home production or childcare. Therefore, by forming a partnership, both men and women are better off from specialization. Second, Becker views the family as an entity which produces and raises children. In this case, a large part of gains from marriage arises from having children. Third, by combining a couple's resources, gains from marriage also come about from economies of scale.

Vella and Collins (1990) as well as Siow (1993) use Becker's notions of marital selection to derive additional results. Utilizing the fact that men remain fertile longer than women, Vella and Collins (1990) argue that older men become relatively more valuable. This leads to "a positive age differential in favor of husbands" (p. 363). Siow (1998) puts it another way: Young fecund women become relatively scarce by being fertile a longer period of their lives. As such, young fertile women become more costly. This leads to an age disparity whereby husbands are older than their wives 
because high wage fertile men can better afford these young women. Giolito (2003) investigates the impact of different male and female fecundity horizons in the context of a two-period two-sided search model. He finds fecundity by itself can explain the age gap at first marriage. ${ }^{5}$

A marital characteristic economists do not readily consider is the educational gap, also prevalent between husbands and wives. ${ }^{6}$ Educational differences between husbands and wives, while narrowing and even reversing in a number of countries, continue to pervade (UN State of the World Population Report, 1997 and Quisumbing and Hallman, 2005). Educational differences lead to specialization in the same way as age differences do. As such, it is important to model not only the husband-wife age gap, but also to model why men tend to be more educated than their wives. To do so, we also make use of the fact that females have shorter fecundity horizons than men. But, in addition, we make use of the fact that schooling takes time to acquire. In the extreme two-period case, one can assume education takes the full first time period, which means the educated put off children to the second period. ${ }^{7}$ For women, this means foregoing children entirely, given women's fecundity limitation.

Our model yields a number of predictions regarding the impact of changes in the demand for children. Most relevant is that husbands are older than their wives and husbands are more educated than their wives the more children they aspire to have.

\footnotetext{
5 This contrasts with Bergstrom and Bagnoli (1993) who reach the same conclusion about the husband-wife age gap via a waiting game in which "males who regard their prospects as unusually good choose to wait until their economic success is revealed before choosing a bride." Sociologists' explanations of the husband-wife age gap are more descriptive. For example, Shorter (1975: pp. 337-339) presents an extensive table with cross-national historical data spanning 1655-1970 indicating that the percentage of husbands more than five years older than their wives averages about $50 \%$ whereas the percentage of wives five or more years older than husbands for the same countries and same dates averages only about 14\%. Knodel (1988: p. 138) examines husband wife age differences which vary between 3.1 and 4.8 across four regions of Germany between 1700 and 1899, and during this time period, from 2.0 for unskilled husbands to 6.8 for farmers. Poppel et al. (2001: p. 12) looks at historical age homogamy in the Netherlands, finding that "age differences between spouses ... have become much smaller ... [in] the last century and a half."

${ }^{6}$ Sociologists have descriptively examined educational differences. For example, Rockwell (1976) attributes 1910-1970 declines in the US educational homogamy across marital cohorts to overall male and female educational distributions becoming more similar. Mare (1991) extends this analysis of the homogamy trends through the 1980s claiming homogamy increased ... from the 1930s to the 1980s (p. 15). Kalmijn (1991) argues that this increased educational homogamy is at the expense of religious homogeneity.

${ }^{7}$ Gustafsson and Kalwij ( 2006) serves as an example illustrating that education delays fertility.
} 
Further, changes in government policies that influence the demand for children, such as China's one-child policy, can influence husband-wife age and educational gaps. Thus after 1980 when the Chinese government initiated a "one-child policy" in order to control its large population growth, we predict the husband-wife age gap at first marriage to decline and husband-wife educational differences to narrow. Similarly, any other policies that affect the demand for children will influence these marital demographics. Such policies might entail lump-sum taxes or subsidies which change the cost of having children, such as tax credits for daycare. Also, factors could include institutional considerations such as living environments. In this regard, farm families usually value children more than non-farm families. In contrast, urban areas often make children more costly. Thus we would predict smaller husband-wife age and educational disparities among urban families.

\section{A Two-period Model}

In this section we develop a two sided search model. Similar to Vella and Collins (1990), Siow (1993) and Giolito (2003) we postulate male and female heterogeneity comes from different fecundity horizons. Further we expand Giolito's (2003) model by introducing education along with the demand for children into the marriage search model.

\subsection{Assumptions}

We assume a continuum of single women of measure $F(t)$, and of single men, $M(t)$. We focus on the steady state. In time $\mathrm{t}$, there are $\mathrm{F}$ females and $\mathrm{M}$ males. Males and females of a given age and education are homogeneous except for their potential fecundity. Further, we assume individuals (males and females) are of either high or low ability. Ability affects the proclivity one goes to school, and going to school puts off marriage (Atkinson and Glass, 1985). ${ }^{8}$ For a woman, putting off marriage

\footnotetext{
${ }^{8}$ As a check, we tabulate number of children born against husband's and wife's age at marriage and husband's and wife's levels of school for the Chinese data we will use in the empirical section. We find an inverse correlation for each. More schooling is associated with few children and those getting married at a younger age have more children. These data are given in Appendix A.
} 
decreases her capacity to have children. ${ }^{9}$ All participants in the marriage market sort based on their age and education levels which are related to their fecundity horizons. For simplicity, we assume both men and women live for two periods. Men are fertile for both periods (at all ages), but women are fertile only during the first period (when they are young). Since education directly affects a woman's capability of having children, and since children affect the utility gained from marriage, we view education as another factor that affects marital decisions. We assume all young people are low educated but some of them are more intelligent (high ability) than their peers. We assume these highly intelligent young men and women can (but not necessarily) acquire schooling by the time they become old. ${ }^{10}$ We assume the young low intelligent men and women do not have the mental capacity for additional schooling, and thus remain less educated.

\subsection{Payoffs}

As was indicated, both men and women can live two periods, but women are assumed to have shorter fecundity horizon than men, that is, only young women are fertile while both young and old men are fertile. A single man or woman will meet only one member of the opposite sex at each period. We assume meeting probabilities are independent of one's ability or education level. They decide whether to propose or not by comparing current utility while being single with the possible utility obtained from matching. When a woman matches with a man and vice versa, the specific utility that the woman obtains from the man and the man from the woman are considered as an independent random draw from uniform distributions $G_{m}(y)$ and $G_{f}(x)$ respectively. Assume $y \sim[0,1]$ and $x \sim[0,1]$, where $\mathrm{y}$ and $\mathrm{x}$ refer to "type" or "quality" of men and women. Both $x$ and $y$ contain observed or unobserved characteristics.

\footnotetext{
${ }^{9}$ We only consider the demand for children measured by number of children. As such, we neglect such issues as child spacing (i.e., having more children over fewer years) or quantity-quality tradeoffs (i.e., having fewer children, but investing more heavily in each's human capital.)

${ }^{10}$ More specifically, in our two-period model, going to school precludes women from having children at all; but this rigid assumption could be relaxed by assuming school simply decreases the probability of getting pregnant.
} 
One sets a reservation value of one's potential spouse based on the maximization of expected utility. We assume an individual's potential marital payoff results from four aspects of the marriage: the marriage partner's quality, the marriage duration, the utility of having children, and one's own and one's spouse's education. Payoff matrices are given in Tables 1 for women and Table 2 for men. We assume zero (marital) utility during the period the individual remains single. We assume marriage yields women a level of utility equal to $y$, and men a level of utility equal to $x$; but that these levels of utility are augmented depending on own and partner quality, marriage duration, and demand for children. We define the parameter $(k)$ to be the demand for children (nominated in number of kids). We assume desiring more children raises the utility of marriage. For simplicity, we specify this by treating $k$ as a multiplicative factor. Thus $k$ is a parameter designated to raise utility multiplicatively by the desired number of children $(k)$.

We assume education to enter utility in either of two ways. First, education increases a person's desirability because education is positively related to income, obviously an appealing marriage market characteristic. We denote the extra utility from a partner's high education level to be the parameter r. Second, education raises opportunity costs of children and serves as a substitute to the benefits children bring. This latter effect is denoted as $e(e>1)$ in the denominator of the male payoff matrix in Table 2. The parameter $\beta$ is the discount rate so that $(0<\beta<1)$.

One can easily justify the payoffs given in Tables 1 and 2 based on this notation and the assumptions regarding payoffs. Each table is divided into sixteen possible matches arising out of own and partner age (young and old), ability and schooling (low and high) levels. Thus an old woman's utility from marrying a low educated young or old man is $y$, since the marriage lasts only one year and produces no children (columns 3 and 4, rows 1, 2, and 4 of Table 1). Should she marry a highly educated 
man, her utility would be $y r$, where $r$ is the rate at which utility is augmented based on a highly educated spouse. Similarly, a young woman marrying an old man has a one-year marriage (old husbands die), but they can have children. The wife's utility is $k y$ if the husband is not educated, and kyr if the husband is educated. A young woman's marriage to a young man lasts two periods and produces children. Thus, her utility is $k(1+\beta) y$ (column 1 and 2, row 1 and 2), independent of her spouses ability because we assume an intelligent person who gets married early in life gives up the opportunity to go to school in order to support children. Table 2 contains comparable payoffs for males except men's utility from marriage is $x$ instead of $y$. In addition, we assume education can serves as a substitute for children in that men can rely on own education to enhance wages in old age. As such, the utility of high educated old men contains $e(e>1)$ in the denominator, partially offsetting the positive direct utility gain children provide.

\subsection{Optimization}

Based on the payoff matrices, men and women respectively determine minimally acceptable quality characteristics for potential spouses based on maximizing expected utility over the two time periods. For young low and high ability women, this amounts to maximizing total discounted utility by choosing optimal male reservation characteristics (i.e., minimum male qualities) based on

$$
V_{f_{1, s}}=\max \left\{\gamma_{f_{1, s}} U_{f_{1, s}}+\left(1-\gamma_{f_{1, s}}\right) \beta U_{f_{2, s}}\right\} \quad s=l, h
$$

where $\gamma_{f_{1, s}}$ is the probability young (low and high ability) women get married at period $1 .{ }^{11}$ Of course, this probability $\gamma_{f_{1, s}}$ is a function of meeting probabilities $\left(P_{f_{1 s}}^{m_{1 s}}, P_{f_{1 s}}^{m_{2 s}}\right)$ and reservation characteristics $\left(R_{f_{1 s}}^{m_{1 s}}, R_{f_{1 s}}^{m_{2 s}}\right)$ for young and old low and high ability men, so that $\gamma_{f_{1, s}}=\gamma_{f_{1, s}}\left(P_{f_{1 s}}^{m_{1 s}}, R_{f_{1 s}}^{m_{1 s}}, P_{f_{1 s}}^{m_{2 s}}, R_{f_{1 s}}^{m_{2 s}}\right)$. Utility functions $U_{f_{1 s k}}$ and $U_{f_{2, S}}$ are defined in Appendix B. They are functions of these reservation values

\footnotetext{
${ }^{11}$ To be clear on notation, the subscript $f$ denote female, the further subscript 1 denotes young, and $s$ denotes low $(l)$ or high $(h)$ ability. In the second period, the young woman becomes old; hence $f_{2 s}$.High ability individuals go to school if they do not marry in the first period.
} 
as well as the payoff matrix parameters given in Tables 1 and 2.

Similarly, young men maximize their total discounted utility by choosing the optimal female reservation characteristics for potential spouses based on maximizing expected utility over the two time periods. For young, low and high ability men, this amounts to maximizing total discounted utility by choosing optimal female reservation characteristics (i.e., minimum female qualities) based on

$$
V_{m_{1, s}}=\max \left\{\gamma_{m_{1, s}} U_{m_{1, s}}+\left(1-\gamma_{m_{1, s}}\right) \beta U_{m_{2, s}}\right\} \quad s=l, h
$$

where $\gamma_{m_{1, s}}$ is the probability young (low and high) ability men get married at period 1. This probability $\gamma_{m_{1, s}}$ is a function of meeting probabilities $\left(P_{m_{1 s}}^{f_{1 s}}, P_{m_{1 s}}^{f_{2 s}}\right)$ and reservation characteristics $\left(R_{m_{1 s}}^{f_{1 s}}, R_{m_{1 s}}^{f_{2 s}}\right)$ for young and old low and high ability men, so that $\gamma_{m_{1 s}}=\gamma_{m_{1, s}}\left(P_{m_{1 s}}^{f_{1 s}}, R_{m_{1 s}}^{f_{1 s}}, P_{m_{1 s}}^{f_{2 s}}, R_{m_{1 s}}^{f_{2 s}}\right)$. Utility functions $U_{m_{1, s}}$ and $U_{m_{2, s}}$ are defined in Appendix B. They are functions of these reservation values as well as the payoff matrix parameters given in Tables 1 and 2 .

\subsection{Reaction Functions Within A Steady State Equilibrium}

The solutions to the optimization problems are the reservation characteristics set by different groups (old and young, low and high ability, and low and high schooling) of men and women. They are $R_{m_{1, l}}^{f_{1, l}}, R_{m_{1, l}}^{f_{1, h}}, R_{m_{1, l}}^{f_{2, l}}, R_{m_{1, l}}^{f_{2, h}}, R_{m_{1, h}}^{f_{1, l}}, R_{m_{1, h}}^{f_{1, h}}, R_{m_{1, h}}^{f_{2, l}}, R_{m_{1, h}}^{f_{2, h}}, R_{f_{1, l}}^{m_{1, l}}, R_{f_{1, l}}^{m_{1, h}}$, $R_{f_{1, l}}^{m_{2, l}}, R_{f_{1, l}}^{m_{2, h}}, R_{f_{1, h}}^{m_{1, l}}, R_{f_{1, h}}^{m_{1, h}}, R_{f_{1, h}}^{m_{2, l}}$, and $R_{f_{1, h}}^{m_{2, h}}$. In equilibrium, high and low ability young men and women should set an optimal reservation value so that they are indifferent between marrying when young and remaining single until the second period. These equilibrium conditions can be depicted as follows:

$$
\begin{aligned}
& k(1+\beta) R_{f_{1, l}}^{m_{1, l}}=k(1+\beta) R_{f_{1, l}}^{m_{1, h}}=k R_{f_{1, l}}^{m_{2, l}}=k r R_{f_{1, l}}^{m_{2, h}}=\beta U_{f_{2, l}} \\
& k(1+\beta) R_{f_{1, h}}^{m_{1, l}}=k(1+\beta) R_{f_{1, h}}^{m_{1, h}}=k R_{f_{1, h}}^{m_{2, l}}=k r R_{f_{1, h}}^{m_{2, h}}=\beta U_{f_{2, h}} \\
& k(1+\beta) R_{m_{1, l}}^{f_{1, l}}=k(1+\beta) R_{m_{1, l}}^{f_{1, h}}=R_{m_{1, l}}^{f_{2, l}}=r R_{m_{1, l}}^{f_{2, h}}=\beta U_{m_{2, l}}
\end{aligned}
$$




$$
k(1+\beta) R_{m_{1, h}}^{f_{1, l}}=k(1+\beta) R_{m_{1, h}}^{f_{1, h}}=R_{m_{1, h}}^{f_{2, l}}=r R_{m_{1, h}}^{f_{2, h}}=\beta U_{m_{2, h}}
$$

The four left hand terms in each equation indicate the respective low and high ability female and male utilities when marrying young and old, low and high ability males in the first period. These values are obtained from parameters contained in the payoff matrices in Tables 1 and 2, multiplied by the respective $\mathrm{x}$ and $\mathrm{y}$ values of the spouses quality (i.e., the reservation quality given that these are uniformly distributed between zero and one).

The far right-hand term of each equation is the utility a low or highly educated male and female would have in period two if each put off marriage until that time period. Because both low and highly educated males and females set reservation characteristics to zero (i.e., $R_{f_{2 s}}^{m_{1 s}}=0, R_{f_{2 s}}^{m_{2 s}}=0, R_{m_{2 s}}^{f_{1 s}}=0$, and $R_{m_{2 s}}^{f_{2 s}}=0$, meaning each will take anyone because there is no other chance to get married), each obtains a utility equal to what would be obtained from the average quality spouse ( $\bar{y}$ or $\bar{x})$ weighted by the product of the probability of meeting each type spouse and the respective utility augmentation parameter $(k, r$, and $e)$ taken from Tables 1 and 2 . These (derived in Appendix B) are:

$$
\begin{aligned}
& U_{f_{2, l}}=\left(p_{f_{2, l}}^{m_{1, l}}+p_{f_{2, l}}^{m_{1, h}}+p_{f_{2, l}}^{m_{2, l}}+p_{f_{2, l}}^{m_{2, h}} r\right) \bar{y} . \\
& U_{f_{2, h}}=V_{f_{2, h}}=\left(p_{f_{2, h}}^{m_{1, l}}+p_{f_{2, h}}^{m_{1, h}}+p_{f_{2, h}}^{m_{2, l}}+p_{f_{2, h}}^{m_{2, h}} r\right) \bar{y} . \\
& U_{m_{2, l}}=\left(p_{m_{2, l}}^{f_{1, l}} k+p_{m_{2, l}}^{f_{1, h}} k+p_{m_{2, l}}^{f_{2, l}}+p_{m_{2, l}}^{f_{2, h}} r\right) \bar{x} . \\
& U_{m_{2, h}}=\left(p_{m_{2, h}}^{f_{1, l}} \frac{k}{e}+p_{m_{2, h}}^{f_{1, h}} \frac{k}{e}+p_{m_{2, h}}^{f_{2, l}}+p_{m_{2, h}}^{f_{2, h}} r\right) \bar{x}
\end{aligned}
$$

Solving the above yield reaction functions in which reservation qualities become functions of the parameters and meeting probabilities.

From these reaction functions, one can derive the effect of exogenously increasing the demand for children on the spousal reservation qualities one would set. As such, 


$$
\begin{array}{llll}
\frac{\partial R_{m_{1, l}}^{f_{1, l}}}{\partial k}<0 & \frac{\partial R_{m_{1, l}}^{f_{1, h}}<0}{\partial k} & \frac{\partial R_{m_{1, l}}^{f_{2, l}}}{\partial k}>0 & \frac{\partial R_{m_{1, l}}^{f_{2, h}}}{\partial k}>0 \\
\frac{\partial R_{m_{1, h}}^{f_{1, l}}}{\partial k}<0 & \frac{\partial R_{m_{1, h}}^{f_{1, h}}<0}{\partial k} & \frac{\partial R_{m_{1, h}}^{f_{2, l}}}{\partial k}>0 & \frac{\partial R_{m_{1, h}}^{f_{2, h}}}{\partial k}>0 \\
\frac{\partial R_{f_{1, l}}^{m_{1, l}}}{\partial k}<0 & \frac{\partial R_{f_{1, l}}^{m_{1, h}}}{\partial k}<0 & \frac{\partial R_{f_{1, l}}^{m_{2, l}}}{\partial k}<0 & \frac{\partial R_{f_{1, l}}^{m_{2, h}}}{\partial k}<0 \\
\frac{\partial R_{f_{1, h}}^{m_{1, l}}}{\partial k}<0 & \frac{\partial R_{f_{1, h}}^{m_{1, h}}}{\partial k}<0 & \frac{\partial R_{f_{1, h}}^{m_{2, l}}}{\partial k}<0 & \frac{\partial R_{f_{1, h}}^{m_{2, h}}}{\partial k}<0
\end{array}
$$

Each makes intuitive sense. For example, $\frac{\partial R_{m_{1, l}}^{f_{1, l}}}{\partial k}<0$ implies males are less picky (lower reservation quality) in their initial (first time period) search for young women as their demand for children rises. On the other hand, $\frac{\partial R_{m_{1, l}}^{f_{2, l}}}{\partial k}>0$ indicates these same men are more picky (higher reservation quality) when meeting an older woman, consistent with older women being less desirable as children become more important.

These reaction function derivatives imply the more important it is to have children (higher $k$ ), the lower the reservation value a young man will set for a young woman than for an old woman, meaning young men prefer young women to old women. The same applies to old men, as well. As for young women, the more important it is to have children, the lower the reservation value they would set in order to marry early.

\subsection{The Relationship Between the Demand For Children and the Age and Education Gaps Between Husbands and Wives}

Let $p_{f_{1}}^{m_{2}}$ represent the probability that a young woman marries an old man. Let $p_{m_{1}}^{f_{2}}$ be the probability that a young man marries an old woman. Based on Appendix B,

$$
\frac{\partial p_{f_{1}}^{m_{2}}}{\partial k} \propto-\frac{\partial R_{f_{1, l}}^{m_{2, l}}}{\partial k}-\frac{\partial R_{f_{1, l}}^{m_{2, h}}}{\partial k}-\frac{\partial R_{f_{1, h}}^{m_{2, l}}}{\partial k}-\frac{\partial R_{f_{1, h}}^{m_{2, h}}}{\partial k}>0
$$




$$
\frac{\partial p_{m_{1}}^{f_{2}}}{\partial k} \propto-\frac{\partial R_{m_{1, l}}^{f_{2, l}}}{\partial k}-\frac{\partial R_{m_{1, l}}^{f_{2, l}}}{\partial k}-\frac{\partial R_{m_{1, h}}^{f_{2, l}}}{\partial k}-\frac{\partial R_{m_{1, h}}^{f_{2, h}}}{\partial k}<0
$$

$\frac{\partial p_{f_{1}}^{m_{2}}}{\partial k}>0$ implies the greater the demand for children, the greater possibility that a young woman marries an old man; $\frac{\partial p_{m_{1}}^{f_{2}}}{\partial k}<0$ means the greater the demand for children, the lower possibility that an old woman marries a young man. Therefore, the greater demand for children the greater the age gap at first marriage between husbands and wives.

Let $p_{f_{h}}^{m_{l}}$ represent the probability that a high-educated woman marries a man with low ability or low-education. Let $p_{m_{h}}^{f_{l}}$ represent the probability that a high-educated man marries a woman either low ability or low-education. Again, based on Appendix $\mathrm{B}, \frac{\partial p_{f_{h}}^{m_{l}}}{\partial k}<0$. The negative sign implies the greater demand for children, the lower the possibility that a high educated woman marries a man either low ability or low-education. Thus, a greater demand for children will decrease the education gap between a husband and wife, measured as husband's minus wife's schooling levels.

At the same time, $\frac{\partial p_{m_{h}}^{f_{l}}}{\partial k}>0$. The positive sign implies the greater demand for children, the greater the possibility that an old high educated man marries a woman of either low ability or low-education. This will increase the education gap between a husband and wife. Therefore, the greater demand for children the greater the education gap between a husband and wife.

\section{Stylized Facts Regarding Husband and Wife Age and Educational Differences}


Demographers use the singulate mean age at marriage (SMAM) to compute a population's mean age at marriage. The SMAM formulation, developed by Hajnal (1953), uses census type data on the proportion of a population's single people at each age (assuming all first marriages have taken place by age 50). It is the sum, up to age 50 , of the difference between the proportion single at age $\mathrm{x}$ and the proportion single at age 50 divided by 1.0 minus the proportion single at age 50

$$
S M A M=\frac{1}{1-p_{50}} \sum_{x=0}^{50}\left(p_{x}-p_{50}\right) .
$$

Intuitively, this is the weighted average of the ages at which individuals get married up to age 50 .

SMAM data are widely available for many countries. In a recent United Nations compilation, the female SMAM varies from 17.6 (Niger) to 31.8 (Sweden) and for men from 22 (Nepal) to 35.4 (Dominica). Typically husbands are older than their wives, but the gender marital age gap varies widely. In Gambia it is 9.2 years. In San Marino the mean marital age gap is -0.2 years. It is the only country out of 235 where wives are older than their husbands. Africa is the continent with the highest average age gap at first marriage (Table 3). Of the 20 countries with the highest husband-wife age gaps, 16 are in Africa. Africa also has one of the highest fertility levels in the world. Worldwide the average SMAM difference between males and females is around 5 years.

Though the overall fertility level is decreasing worldwide, there are a number of countries experiencing meager declines in fertility. These latter countries constitute 21 developing countries where fertility rates declined by less than one child per woman since 1970. Of these countries, thirteen are from sub-Saharan Africa. The large age gap at first marriage and the high fertility level in Africa are basically associated with high infant mortality, low healthcare conditions, and few family planning policy controls. 
The average SMAM difference between males and females in Asia is around 3 years. Within Asia the age gap at first marriage varies dramatically with a minimum of around 1 year in Myanmar and a maximum of around 7 years in Afghanistan and Bangladesh. Developed countries such as Japan, Korea and Singapore are experiencing low fertility levels due to rapid growth in their economies, and religious beliefs that do not necessarily promote fertility.

Europe is the continent with lowest SMAM difference between males and females. As mentioned above, the data shows a minimum of -0.2 years in San Marino (meaning that in San Marino wives are actually on average 0.2 years older than their husbands) and a maximum of 4.9 in Greece. North Europe is an area with a low age gap at first marriage and high social welfare. The SMAM difference is smaller in Latin America and the Caribbean than in Africa or Asia. Similar to the North European countries, there are many consensual unions in this area, therefore, the data may not exactly reflect the true age at first marriage.

The mean age at marriage also varies over time. In the US (Figure 1) male mean age at first marriage was 26.1 in 1890 . It dipped to 22.5 in 1956 , only to rise again to 26.9 in 2002 . For women the mean age at first marriage was 22.0 in 1890 , but fell to 20.1 in 1956, and like men rose to 25.3 in 2002. However, interestingly, the husband-wife age gap has not exhibited the same cyclicality, but instead declined relatively steadily from 4.1 in 1980 to 1.6 in $2002 .{ }^{12}$ Note, this decline in the husband-wife age gap is consistent with our hypothesis of a direct relation between fertility and the marital age gap.

Historical data for Canada (Figure 2) is very similar to the US. Age at first marriage behaves cyclically. It falls for both men and women until the early 1930s, rises for both until 1940, then falls until the 1970s, and finally rises through the 1990s.

\footnotetext{
12 This pattern is consistent with Rolf and Ferrie (2008) who examine three other measures of age homogamy besides the average husband-wife age gap we adopt in this paper.
} 
As with the US, the husband-wife age gap declined steadily.

Reaching conclusions about age at marriage (as distinct from the husband-wife age gap on which we concentrate) based solely on data from the last five decades may lead to misleading inferences. For example, a number of marriage models argue age at marriage is related to the demand for children. As evidence, they claim the trend of the currently rising age at first marriage is consistent with the decline in fertility. However, as exhibited above, as well as in Figures 1-2, age at first marriage has not risen steadily despite steady declines in fertility. To illustrate, U.S. fertility declined since 1800 from 7.04 (births per 1000 woman) to 2.22 in 1940. Yet the age at marriage declined (not rose) more or less steadily during this time period. From 1960-1990, age at first marriage rose dramatically, but fertility rates declined modestly from 2.98 to 2.00 (when compared to the gigantic 1800-1940 decline). In short, the cyclicality in age at marriage does not mirror the more or less monotonically declining time trend in fertility, as argued by many theories of marriage. ${ }^{13}$ On the other hand, historical patterns indicate the husband-wife age gap has narrowed as fertility rates declined. This pattern is easily seen in Figures 1 and 2, and is consistent with the theory we outlined in the previous section.

We have not found long-term data on husband-wife educational differences. However, there are international data on overall male-female educational differences that can be culled from the World Resources Institute EarthTrends website. ${ }^{14}$ We

\footnotetext{
${ }^{13}$ Early studies on the gender wage gap suffered from a similar fault. These studies all relied on 1960-1980 U.S. Census and Survey of Economic Opportunity data. Using these data researchers concluded a constant male-female wage gap because women earned roughly 59 cents on the dollar throughout this time period. It was not until Goldin's (1990) book along with an examination of post -1980 data that scholars found out women's wages increased secularly, with 1960-1980 being the exception.

14 EarthTrends's website is: http://earthtrends.wri.org. Information on female and male education levels can be found at: http://earthtrends.wri.org/searchable_db/results.php?years=all\&variable_ID=1116\&theme=4\&country_ID=all\&co $\underline{\text { untry_classification_ID=all }}$

and

http://earthtrends.wri.org/searchable_db/results.php?years=all\&variable_ID=1117\&theme $=4 \&$ country_ID=all\&co untry_classification_ID=all.
} 
summarize these in Table 3 along with the data on the already discussed husband-wife age gap based on United Nations SMAM data. These educational differences go from a 1.7 male advantage in Middle Africa to a 1.58 female advantage in Northern Europe. In the US married women now have a 0.67 year advantage. According to our theory both husband and wife age and educational differences should be positively correlated if the underlying factor determining each is related to fecundity. To the extent the schooling differences we observe reflect husband-wife mean levels of education, we should see a positive correlation across regions, and we do $(\rho=.73)$. Those regions with high fertility have both a high husband-wife age gap as well as a large gap in schooling between men and women. This significant positive correlation is also illustrated in Figure 3

This predicted positive relationship between fertility and husband-wife age and educational differences can be visualized more directly by incorporating country-specific fertility data. ${ }^{15}$ Figures 4 and 5 illustrate this positive correlation. Countries with higher average fertility exhibit larger male-female educational differences and bigger husband-wife age disparities. However, these cross-country comparisons should be viewed only as illustrative because at least three problems mar such comparisons. First, as already mentioned, the education data do not specifically measure husband-wife differences. Adjusting for the proportion married might mitigate, but doesn't solve the problem. Second, fertility rates apply to the country as a whole, not necessarily to married couples. Data on the proportion of births out of wedlock, if available, might help, but these data would not fix the problem completely. Third, fertility need not be exogenous. For these reasons we look to China's one-child policy as a way to test our theory.

\subsection{Empirical Strategy: China as a Natural Experiment}

\footnotetext{
15 World Bank Development Indicators (2006)
} 
Our empirical strategy is to find statistical evidence regarding our two main predictions. We seek confirmation (1) that husband-wife age differences are positively related to fertility, and (2) that husband-wife educational differences are positively related to fertility. To substantiate these propositions, we explore evidence based on a natural experiment using Chinese data from before and after the "one-child" law. As is well known, China adopted the law in 1980 essentially outlawing more than one child per family. The law effectively decreased the demand for children. As such, China's 1980 legislation permits one to study marital patterns before and after the law went into effect. ${ }^{16}$ To better understand why this is an ideal natural experiment enabling us to treat the law as an exogenous event we give a brief history of Chinese fertility policy. ${ }^{17}$ Following this history, we describe the relevant data and outline how we identify the effects of fertility via regression and difference-in-differences approaches which we use to measure the law's impact. In addition, we describe how we further identify the effects via community variations in fines and subsidies for violating and adhering to the one-child law.

\subsection{A Brief Summary of China's Family Planning Policy}

In the 1950s, Mao Zedong urged the Chinese people to procreate in order to strengthen the country. In 1949, the population on the mainland was only about 542 million. However, under the slogan "more people more power" China's population grew rapidly increasing to about 807 million by 1969 . In the 1970 s when the baby

\footnotetext{
${ }^{16}$ Out of wedlock births are very rare in China, certainly in the time period under study. One reason is that such births are illegal. Single mothers must pay a large fine and will find it difficult to register the baby. Thus out of wedlock births are far less important in China than most other countries. As such, this is a factor we do not have to, nor do we, consider.

17 Of course, China experienced other changes. Most notably, since 1978/1979 China moved from politically-based to economically-based policy decisions. This change entailed promoting education and technology. To do so, the government reintroduced university entrance exams and sought more gender equality in the right to higher education. These changes could have had dramatic effects, but in reality, since the university system was destroyed in 1967-1977, the rise in university attendance relative to the size of population was not as dramatic as one might think. In 1978 the college graduate pool amounted is 165,000; in 1984 this figure was only 287,000. Thus, we suspect this change to be too weak to discern. Nevertheless, even if concurrent, both the one-child policy and the policy promoting education decrease the demand for children, thereby working in the same direction. Thus, we can still take the change in demand as exogenous since both policies were unexpected. The only caveat is not all the demand change can be attributed solely to the one-child law. For ease of exposition, we refer only to the one-child law as the factor instigating the change in demand for children.
} 
boomers of the 1950s and 1960s were entering their reproductive years, the Chinese government viewed strict population containment as essential to alleviate social, economic, and environmental burdens. At that time, the Central government launched a voluntary birth control campaign advocating each citizen delay marriage, have fewer births, and space children widely apart. The policy was not compulsory but nevertheless moderated fertility. However, fertility still remained well above the replacement rate. For that reason, by the end of 1970s, the policy was replaced by mandatory legislation directly targeting the number of children per family. The Chinese National People's Congress proposed the "family planning policy" in its third session of the fifth National People's Congress in September 1980.

To put meat on the policy, so to speak, and make it more effective, one child families were rewarded while violators were punished. The rewards generally included subsidies, and the punishments usually entailed levying fines on above-quota-births. Because the overall amount of subsidies were limited, the reward was less effective than the punishment, especially in rural areas; nevertheless both worked in tandem. As a result, the Chinese population structure and the traditional family composition changed rapidly. Since the implementation of the one-child law, China's female TFR (Total Fertility Rate) decreased from about 2.8 births per woman in the 1979 to 1.33 births per woman by 2005 (2005 National 1\% Population Sample Survey of China). Since rural fertility was initially higher in the first place, rural fertility declined at a greater pace than urban fertility (though there may be some bias in this comparison because of the hukou system of classifying residence). Taking China's experience as a case study, a natural experiment seems logical given the relatively rapid and unexpected change in policy from Chairman Mao's pro-natalist "more people more power" to the 1980 "one child' legislation.

Of course, during this time period, fertility rates in the rest of the world also decreased; but Chinese fertility decreased more rapidly. This greater fertility decline in China compared to elsewhere is consistent with the law being exogenous and 
unexpected in the sense that Chinese fertility behavior differed from the rest of the world. In addition, China's fertility trend differed from India, also a high population country very similar to China with regard to development and growth. Figure 6 best illustrates these trends. World fertility declined modestly from 1955-1970 as did India's. China's fertility, on the other hand, increased slightly given Chairman Mao's edict to increase birth rates. From 1970-2005 world and Indian fertility rates declined at a slightly faster rate than between 1955-1970. In contrast, China's fertility rate dropped more quickly from 1970-1990, but then from 1990 conformed more to the world and to Indian trends. In short, China's fertility rate differed from the rest of the world, as well as from India. Instead it conforms to expectations based on unique government pro then anti-natalist policies, thus making China an ideal case study for a natural experiment. ${ }^{18}$

\subsection{Data Source and Definitions}

To conduct our empirical analysis, we extract marriage, fertility, age and education data from the China Health and Nutrition Survey (CHNS). In addition, we obtain proprietary data from the community-based CHNS detailing fines and subsidies levied by specific communities on families violating and adhering to the one-child rule. Overall, the CHNS is designed to examine the effects of the economic, health, nutrition, and family planning policies implemented by national and local governments to see how the social and economic transformation is affecting the economic, demographic, health and nutritional status of China's population. The survey contains a sample of about 4400 households with a total of 19,000 individuals in nine provinces. Although the CHNS sample is not nationally representative, it covers both less developed mountain provinces such as Guizhou and Guangxi, and developed coastal provinces such as Jiangsu and Shandong. The proprietary community data contains detailed information on overall health and well-being within each of 181 communities. As just mentioned, it includes community-specific fines for violating the one-child law and indicators of subsidies for those following the law.

\footnotetext{
${ }^{18}$ McElroy and Yang (2000) find similar effects of the Chinese government's policies regarding fertility.
} 
The survey was first conducted in 1989; follow-up surveys were carried out in 1991, 1993, 1997, 2000, 2004 and 2006. ${ }^{19}$

Our analysis is primarily based on the 1993 survey. It has several advantages over other years' surveys, but as will be explained we also use other years' information, as well. First, the total number of children born can only be accurately constructed from the survey of ever married women (SEMW), which was initiated in 1993. Follow-up surveys were carried out beginning in 2000. Second, the 1993 survey contains enough individuals who married before 1979 to enable us to analyze how the one child policy is related to husband-wife age and educational differences.

The SEMW contains information on all live births for ever-married women aged under 52 in the 1993 survey. We use the total number of children a woman gave birth to until 1993 to measure her fertility rate. This gives an indication of whether or not families violated the law by having more than one child after the law was initiated. We view the fertility rate as a proxy for the real demand for children, given that a greater fertility rate is indicative of a higher desire for children. Husband-wife age and educational differences are easily computed given that we have individual data. Of course, our main concern relates to changes in husband-wife age and educational differences resulting from the law and its enforcement.

We present descriptive statistics of the salient variables in Table 4. Because the demand for children is smaller in urban than in rural areas and because urban areas might be affected differently by the one-child law, we present one column for rural areas and another for urban areas. We see rural residents have more children than urban dwellers, and at the same time we observe rural residents to be less educated and marry younger. The husband-wife education gap is larger in rural areas as expected, but the husband-wife age gap is not (probably because they marry at a

\footnotetext{
${ }^{19}$ For additional information on the CHNS see: http://www.cpc.unc.edu/projects/china
} 
younger age). Nevertheless, plotting husband-wife age and educational differences by number of children yield the predicted positive slope in both rural and urban areas (Figures 7 and 8). As can be seen, larger families exhibit wider husband-wife age and educational disparities. We also observe urban communities penalize violators and reward adherents more (bottom rows of Table 4).

\subsection{Empirical Strategy}

Our empirical approach examines fertility as well as spousal age and educational outcomes before and after China's implementation of its one-child policy. In doing so, we examine the raw data prior to and following the policy change for rural and urban areas. First, we employ additional descriptive statistics along with a simple regression framework; second, we use difference-in-differences estimation in which we take account of disparities pertaining to urban and rural inhabitants; and third, we utilize variations in community penalties for violating the law.

We divide the data into three groups depending on marriage date: couples married before 1979 who were not affected by the one child policy; couples married after 1984 who were affected by the one child policy and couples married between 1979 and 1984 who are assumed partly affected by the one child policy. ${ }^{20}$ Summary statistics given in Table 5 will be discussed later. Since the Chinese government implemented a different one child policy in rural and urban areas, we also divide all samples by their place of household registry (known as hukou), and use differences-in-differences to illustrate that the one child policy had dissimilar effects in rural and urban areas.

First we identify the impact of the one-child policy on fertility. We measure

\footnotetext{
${ }^{20}$ Recall that in 1984 the one-child law was calibrated to meet different community needs. Based on Figure 9 we also redid the analysis redefining the Pre and Post variables to be Pre1970 and Post 1970 to reflect the fact that anti-natal policies actually began in 1970 with the less formal "Birth Control Campaign." Also to distinguish the "Birth Control Campaign" from the "One-Child Policy" we performed additional analysis with a set of categorical dummy variables: Pre-1970, 1970-1980, and Post-1980; as well as simply pre-1980 and Post-1980. Each of the results turned out comparable. Thus here we only present the pre- and post- one-child law since these results are the easiest to exposit, most robust, and in our opinion best represent the appropriate time periods.
} 
fertility in two ways. First, as the number of children within the household, and second, whether the household has more than one child. The latter indicates whether families violated the one child policy. According to Table 5, fertility declined from before to after implementation of the one-child policy more for rural than urban residents. Also, we employ the following regression Fer $_{i l t}=\gamma_{0}+\gamma_{1}$ Pre $_{i l}+\gamma_{2}$ Post $_{i l}+\gamma_{3}$ Rural $_{i l}+\gamma_{4}\left(\right.$ Rural $\cdot$ Post $_{i l}+\gamma_{5} X_{i l t}+\gamma_{6} \zeta_{l}+\gamma_{7} \zeta_{t}+\varepsilon_{i l t}$

The dependent variable Fer refers to fertility (measured in the two ways just described above), $\mathrm{X}$ is a vector of individual characteristics (husband's and wife's age and/or education depending on the regression), and $\zeta_{1}$ refers to community-specific dummy variables, $\zeta_{\mathrm{t}}$ refers to year married categorical dummy variables, and $\varepsilon_{\mathrm{ilt}}$ a family-community-time specific error term. ${ }^{21}$ The variable Pre indicates whether the couple married before 1979 and Post indicates the couple married after 1984. Observing $\gamma_{2}<\gamma_{1}$ implies lower fertility after the policy change. The variable Rural indicates a rural household. The coefficient on the interaction between Post and Rural estimates the difference in fertility between rural and urban areas after the policy change. A negative $\gamma_{4}$ implies a bigger effect in rural areas where fertility rates were initially highest. Because the one child policy allows rural families to have more children than urban families, the sign of the coefficient of $\gamma_{4}$ can be positive or negative.

If, as we expect, the one child policy is related to fertility, one could go on to test whether the husband-wife age and education gaps change, as well. These specifications are comparable where the outcome is either the husband-wife age gap or the husband-wife education gap, and the other variables are as defined above.

Outcome $_{i l t}=\alpha_{0}+\alpha_{1}$ Pre $_{i l}+\alpha_{2}$ Post $_{i l}+\alpha_{3}$ Rural $_{i l}+\alpha_{4}\left(\right.$ Rural Post $_{i l}+\alpha_{5} X_{i l t}+\alpha_{6} \zeta_{l}+\alpha_{7} \zeta_{t}+\varepsilon_{i l t}$

\footnotetext{
${ }^{21}$ This specification is similar to the one used by McElroy and Yang (2000). In addition to the above, we reran (7) with chronological year but without categorical dummy year variables. Utilizing this linear time trend reduces the significance of $\gamma_{1}$ and $\gamma_{2}$ somewhat, but leaves the other results intact.
} 
The underlying logic is the same. The effect of the one child policy on husband-wife age and education differences can be estimated by comparing the changes in the husband-wife age gap and the husband-wife education gap before and after the implementation of one child policy and between the areas which are differently affected by the one child policy. One can surmise age and education gaps are affected by the one-child law if we find the $\alpha$ coefficients mirror the $\gamma$ coefficients. In other words, a higher (in absolute value) $\gamma_{2}-\gamma_{1}$ should imply a larger $\alpha_{2}-\alpha_{1}$. In addition, rural areas should exhibit a decrease in the age and educational gaps if rural fertility decreases more.

The community CHNS data also enable us to identify the law's effect yet another way. Under the one-child legislation communities are allowed to fine families that violate, and to reward families that adhere to, the law's provisions. These monetary penalties are given in the CHNS community data. The bottom rows of Table 4 give average fines in rural and urban areas, but the fines also vary between locations within urban and rural domains. Thus another identification strategy, besides examining effects before and after the law, and using the difference in the law's effect between rural and urban areas, is to utilize data on the variation of these fines across locations. Families living in areas with higher fines should exhibit bigger decreases in husband-wife age and education gaps after the one-child law, assuming these fines are exogenous to the family and that communities do not levy fines based on having higher fertility rates in the first place. ${ }^{22}$

\footnotetext{
22 Ebenstein (2010) also uses variation in fines as his identification strategy. He finds that higher fines decrease fertility and are associated with higher ratios of males to females, implying some degree of infanticide. Similarly, McElroy and Yang (2000) use location-specific variation in fines as their identification strategy to measure the effects of the one-child law. However, they use the Household Economy and Fertility Survey and concentrate on 299 births in 1991 of which 91 were above quota. Their data do not contain as extensive information on fines as the CHNS nor do their data contain rewards. Further, they are not concerned with age or education differences between husbands and wives. Of course, the impact of the fines could vary with family wealth. This could be tested by interacting fines and wealth, were the data available. Similarly, one could test whether the impact of fnes
} 
We pursue this avenue in two steps. First we verify that communities with higher fertility prior to the law do not mandate larger fines. To do so, we regress fertility prior to the one child law on fine level after the law. We should observe no correlation between the two, if fines are determined by factors other than fertility. Such a finding would give credence to using these fines as an exogenous variable. ${ }^{23}$

Second, we utilize a similar model as above to examine the effectiveness of these fines. Specifically, we estimate two sets of equations:

Fer $_{i t}=\beta_{0}+\beta_{1}$ Rural $_{i l}+\beta_{2}$ Post $\cdot$ Rural $_{i l}+\beta_{3}(\text { Post } \cdot \text { Fine })_{i l}+\beta_{4}(\text { Post } \cdot \text { Subsidy })_{i l}+\beta_{5} X_{i l t}+\beta_{6} \xi_{t}+\varepsilon_{i l t}$

Outcome $_{i t}=\beta_{0}^{*}+\beta_{1}^{*}$ Rural $_{i l}+\beta_{2}^{*}$ Post $\cdot$ Rural $_{i l}+\beta_{3_{3}}^{*}(\text { Post } \cdot \text { Fine })_{i l}+\beta_{4_{4}}^{*}(\text { Post } \cdot \text { Subsidy })_{i l}+\beta_{5_{5}}^{*} X_{i l t}+\beta_{6}^{*} \xi_{t}+\varepsilon_{i l t}^{*}$

where each of the variables are as previously defined, Fer is a measure indicating violation of the one child law, and Outcome measures the difference in husband-wife age and education. The subscript $i$ depicts the household and $t$ the year the household married. We cannot control for location-specific effects because employing location-specific fines make it impossible to further distinguish specific communities. A negative $\beta_{3}^{*}$ and $\beta_{4}^{*}$ coefficient means lower outcome measures for communities with higher fines.

\subsection{Empirical Results}

We adopt three methods to identify the effects of the one-child law. First, as was explained above, we employ a simple regression to identify the difference in outcome

vary by community wealth, but here it is not clear that fines are exogenous in that they may be related to community wealth.

${ }^{23}$ Of course, other community characteristics such as average income could affect fine levels, as well. 
from before to after the law. Second, we utilize a difference-in-differences approach. Here we examine how rural-urban differences change from before to after the law. Third, we use community variation in fines and subsidies to identify the law's effects.

Begin with the estimation of (5.1) for fertility. The results are presented in Table 6 . Columns (1) - (4) on the upper panel contain the results for fertility measured as number of children, columns (5) - (8) for fertility measured dichotomously as greater than one child (an indication for violating the one-child law),. Clearly $\gamma_{2}-\gamma_{1}$ shows a statistically significant 1.18 decline in urban fertility. This decline in fertility virtually equals the 1.16 (2.34-1.18) births per woman unadjusted (for other variables) figure given in the descriptive statistics Table 5. Adjusting for other variables including 177 specific communities does not alter the results that fertility declined from before to after enactment of the one-child law. In all cases the $\gamma_{1}$ coefficients are positive and the $\gamma_{2}$ coefficients are negative. We obtain similar results when we examine the probability of having more than one child. ${ }^{24}$ On average this probability of having more than one child is about 0.3 units higher before the law, and between 0.2 and 0.7 units lower after the law.

We now turn to equation (5.2) for husband-wife differences. Column (1) - (4) on the lower panel give the results for the husband-wife age gap regression as the outcome measure. Again the difference $\left(\alpha_{2}-\alpha_{1}\right)$ is statistically significant (though $\alpha_{2}$ is not) indicating a decline in the age gap of about 0.63 years which is the same as the value indicated in Table 5. This result is consistent across specifications though slightly smaller when adjusting for each location and a bit larger when adding dummy variables for each year. Again, finding a decline in the husband-wife age difference is consistent with the theoretical model outlined earlier. The impact on the husband-wife education gap (column (5) - (8)) on the lower panel is also apparent. In column (5)

\footnotetext{
${ }^{24}$ These are analyzed with a probit specification, given the dichotomous nature of the dependent variable. Marginal probabilities of a discrete change in the independent variable from zero to one are reported.
} 
the coefficient difference $\alpha_{2}-\alpha_{1}$ indicates an overall decrease in the husband-wife years of schooling to be about 1.74 years. This decline corresponds to the 1.87 decline in Table 5 (2.35-0.48). As with the husband-wife age gap, this result is consistent across specifications though slightly smaller when adding community-specific and year-specific adjustments. The results are in accord with a decline in husband-wife education when fertility intentions fell as a result of the one-child law.

Rural residents tend to have higher fertility than urban residents. Going back to row (3) of the fertility regressions, we find approximately 0.6 more children for rural residents. Similarly, rural residents have at least a 0.22 higher probability of exceeding a one-child per family fertility. Concomitant with more children, the husband-wife education gap is larger in rural areas. On the other hand, this does not appear to be the case with the age gap. One reason for a smaller rural age gap is rural residents marry when they are about 1.3 years younger than urban residents.

The coefficient on the interaction between Post and Rural $\left(\alpha_{4}\right)$ is also negative consistent with the one-child policy having a greater impact in rural than urban areas. $^{25}$ The -.31 post-law*rural interaction term (row (4)) implies a 0.31 birth per woman greater decline in fertility for rural inhabitants. Again this is about equal the 0.34 [(2.97-1.47)-(2.34-1.18)] amount implied by Table 5. Adjusting for specific communities (column (4)) does not alter the results. However, the rural-urban decline in the probability of having more than one child is statistically insignificant except when adjusting for year-specific and location-specific dummy variables (not shown). The husband-wife age gap interaction term implies about a $3 / 4$ year bigger decline in rural areas following the one-child law. This result is consistent across all specifications. On the other hand, the interaction term between post-law and rural for

\footnotetext{
25 Mismeasurement of individuals in the rural areas can help explain the larger observed fertility decline in rural areas. Larger effects can be observed for rural residents to the extent rural residents migrate to urban areas but cannot change their hukou. We have no way of estimating the extent of this bias.
} 
the education difference is positive though insignificant. ${ }^{26}$ This coefficient implies the husband-wife education gap before and after the implementation of the one child policy is smaller in rural than in urban areas which is inconsistent with our prediction based on a larger decline in rural area fertility. One explanation is societal discrimination brought on either by families' or the government's slow response to the changing needs of women's education, what some might call a "boy preference" in rural areas. However, as the economic situation in rural areas improved, replications of the statistical experiment become more consistent with expectations. Table 7 (columns (1) - (4)) contains the same regression using the 2000 Chinese data, and the 2004 data (columns (5) - (8)). Both yield stronger effects of the one-child law in rural areas.

To test whether penalties and subsidies are valid exogenous variables, we regress post-law penalties on pre-law fertility. We measure fertility as the proportion of a community having more than one child. This measure gets at potential violations of the one-child law. We do the analysis for both urban and rural locations as the unit of observation. If penalties (and rewards) are determined independent of fertility, we should find no relationship between these subsidies and the fines and pre-law fertility rates. The results are given in Table 8 . We utilize the two types of fines available for the most communities, as well as a dummy variable indicating whether a family receives a housing subsidy for adhering to the law. All fertility coefficients are statistically insignificant. Thus we find no evidence that communities, originally with higher fertility, levy greater fines to discourage violations of the law. ${ }^{27}$

We utilize equations (5.3) and (5.4) already discussed to test the impact of fines and subsidies. The results are given in Table 9. We present four specifications, denoted by whether we include individual family characteristics and annual

\footnotetext{
${ }^{26}$ This is similar to the results in Table 5 which indicates a 0.7 smaller decline in education in rural compared to urban areas (2.35-0.48)-(2.60-1.42).

${ }^{27}$ Of course, it is possible that fines are related to community wealth or average family income. We did not test for this.
} 
categorical time dummies. ${ }^{28}$ As before, we find rural residents have higher fertility (even adjusting for fines and subsidies), exhibit a smaller husband-wife age difference, and possess a greater husband-wife disparity in education. Again, rural fertility decreases more after the one-child law, as did the rural husband-wife age gap. However, now two additional findings emerge. First, fines appear to have a more deleterious effect on fertility than subsidies. This result may be consistent with prospect theory which argues that individuals value losses more than potential gains; or alternatively it may come about because fines and subsidies are measured differently. We use the logarithm of fines, but by necessity we are forced to use a zero-one dummy variable for the subsidy because no consistent information was available on the value of subsidies across a sufficient number of locations. Second, fines and subsidies are associated with both lower fertility and lower husband-wife age and educational differences. The coefficients indicate that doubling the fine leads to a $18-33 \%$ decline in fertility, a $30-33 \%$ decrease in the husband-wife age gap, and a $40-48 \%$ decrease in the husband-wife education difference.

How relevant are the results to other parts of the world? One way to answer this question is to apply the Chinese estimates to see if they generalize to what we observed earlier regarding inter-country differences. Based on Figure 4, the gradient between fertility and the husband-wife age gap is about $0.6 .^{29}$ Thus, for example, at the extremes Niger and Afghanistan have fertility rates exceeding 6 children per woman and husband-wife age gaps exceeding 6 years, whereas Hong Kong and Spain have fertility rates of about 1.2 and an age gaps less than 2.5. Based on the China one-child law, we observe the number of children to decline by approximately 1.3 and the age gap to decline by about 0.75 years. This implies a regression coefficient of about 0.6 , virtually identical to what was obtained from the cross-national comparison. For education, Chinese data yield an implied coefficient of about 1.2 compared to

\footnotetext{
${ }^{28}$ As already mentioned, we are precluded from introducing a location-specific dummy variable because the variation in fines does not allow us to identify the independent effect of each location.

${ }^{29}$ The regression fit is: Age Gap $=1.77+0.6$ Fertility. For education, the regression line is: Education Gap $=-.42$

+0.52 fertility.
} 
0.52 across countries.

These estimates based on entirely disparate data and techniques are uncannily close. This means the Chinese estimates explain a significant part of inter-country variations. As such, one can say that the estimates may be applicable far beyond the natural experiment from which they originate.

\section{Summary and Conclusions}

In the United States and virtually all other countries, men earn more than women. In 1960 women earned 59 cents on the dollar. Now the wage ratio is about 0.78 . For single-never-married men and women the gap is approximately $5 \%$, but for married men and women the gap still hovers around 30\%. The gender gap for married men and women increases with number of children as well as with the spacing of children. One explanation consistent with these patterns is division of labor in the home. Husbands specialize in market activities and wives in household activities. As a result men invest more in human capital and earn higher wages than their wives. Indeed the husband-wife wage gap widens with years of marriage until children are old enough to leave the home. Household specialization is most likely greatest the higher the number of children and the more widely children are spaced. But why is there division of labor in the first place?

One reason for division of labor is discrimination. If the market rewards men disproportionately more than women for comparable skills it pays for the husband to specialize in market work and women in home work. But specialization can occur even without discrimination.

In virtually all countries and in most marriages husbands are older than their wives. At least in the past, the same spousal difference was true for years of school. Age and educational advantages imply a higher earnings potential. Based on this, 
household specialization makes sense given that husbands have a relative earnings advantage based on being older and more educated than their wives. This paper examines underlying reasons for two patterns inherent in today's marriages, namely husband-wife age and educational differences, both of which are in part responsible for division of labor.

Most of us would claim that children form a basis for marriage. Most would also agree the biological clock ticks differently for men and women. This paper makes use of both of these observations to illustrate that together they lead to age and educational differences between husbands and wives. We employ a two-sided search model to show that the greater the desire for children, the larger the husband-wife age gap and the more likely husbands attain greater schooling levels than their wives.

We give credence to these suppositions taking China's anti-natalist policies as a natural experiment. We show that China's move from a pro-natalist to a mandatory anti-natalist "one-child" policy can be taken as an exogenous change because this policy reversal caused China's fertility patterns to be different than the rest of the world, and different than India a nation to which China is often compared. We find that China's one-child law brought about both a decrease in fertility and a decrease in husband-wife age and schooling differences. A one child per women lower fertility decreases the age gap by about 0.6 years and the schooling gap by over one year. These estimates are obtained from a natural experiment in China, but are very similar to simple cross-national observations. In short, we conclude changes in fertility are associated with changes in marital patterns that easily affect the division of labor in the home.

More specifically, fecundity differences between husband and wife can lead to the age and educational differences (i.e., hypogamy) associated with division of labor in the home. This division of labor, in turn, can help exacerbate the gender wage gap. Hence the plausibility of a biological basis for gender wage differences. As fertility 
declines, as has been the historical trend, marital differences diminish. As these marital differences diminish, so does the division of labor in the home, and the gender wage gap, as well. This appears to be the trend in the US and most other developed countries. 
Figure 1

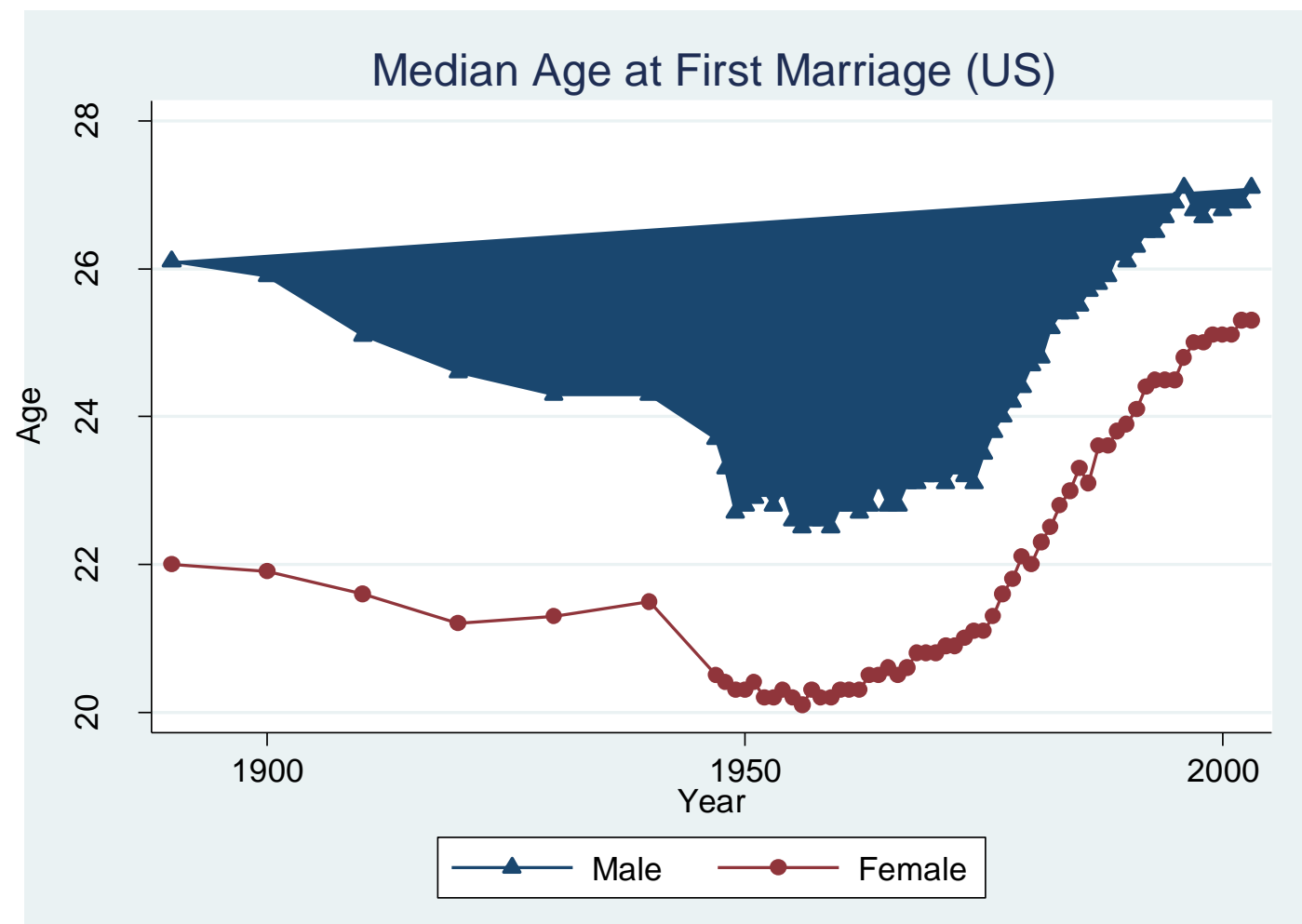

Notes: Figures for 1947 to 1999 are based on Current Population Survey data. Figures for years prior to 1947 are based on decennial censuses. A standard error of 0.1 years is appropriate to measure sampling variability for any of the above estimated median ages at first marriage, based on Current Population Survey data.

Source: http://www.census.gov/population/socdemo/hh-fam/tabMS-2.pdf 
Figure 2: Age at First Marriage: Canada, 1921-1991

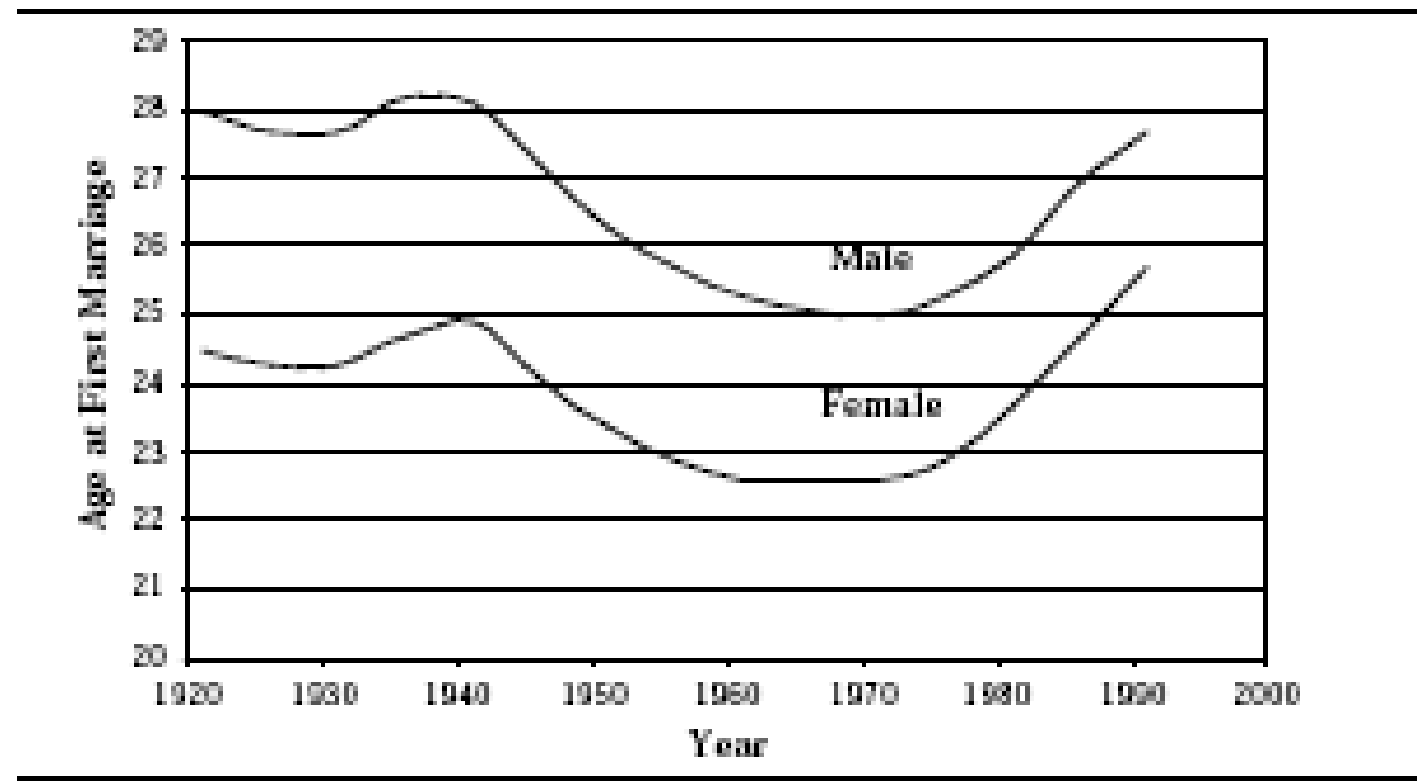

Sounce: Canadian Vital Statistics.

Obtained From: Zheng Wu (1998) “Recent Trends In Marriage Patterns In Canada Policy,” Policy Options

September 1998, p.4. 
Figure 3

Husband-Wife Age and Gender Educational Differences*

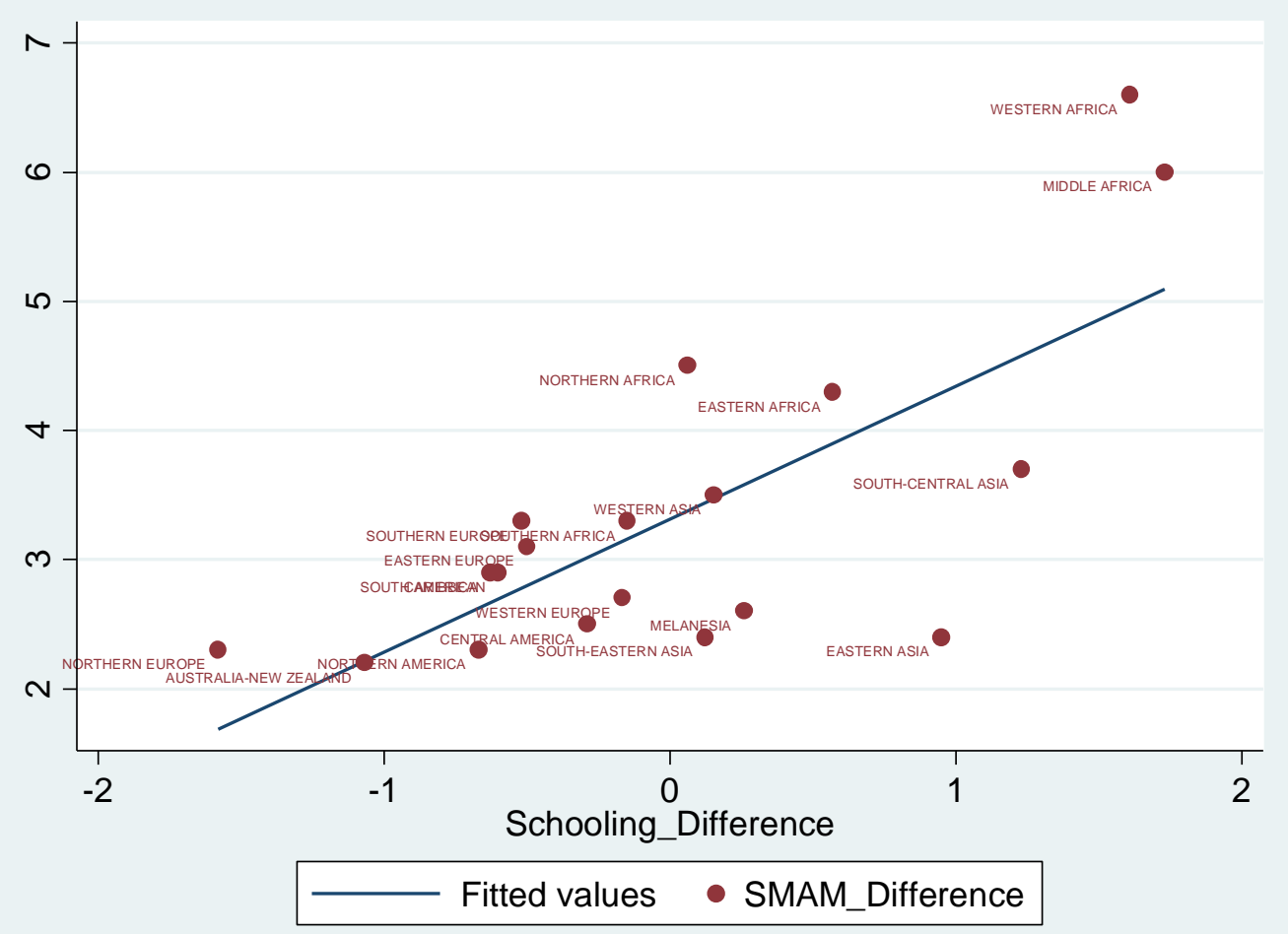

* Computed by authors based on Table 3. SMAM and school differences are measured in years. 
Figure 4

A Cross-National Depiction of Fertility and the Husband-Wife Age Gap*

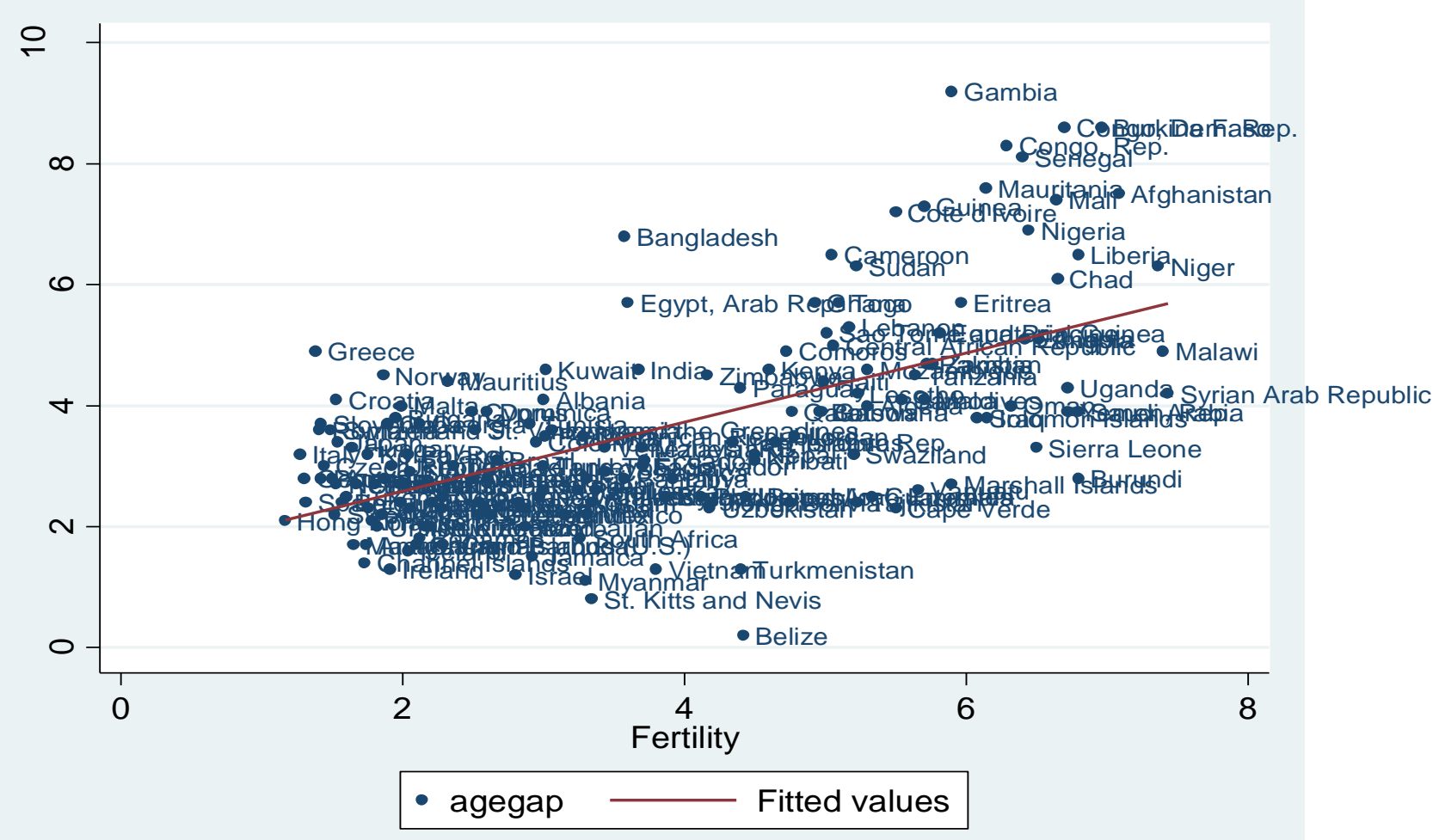

* Computed by authors based on cross-national data described in text. The age gap is measured by number of years, and fertility by the number of children. 
Figure 5

A Cross-National Depiction of Fertility and Male-Female Educational Differences*

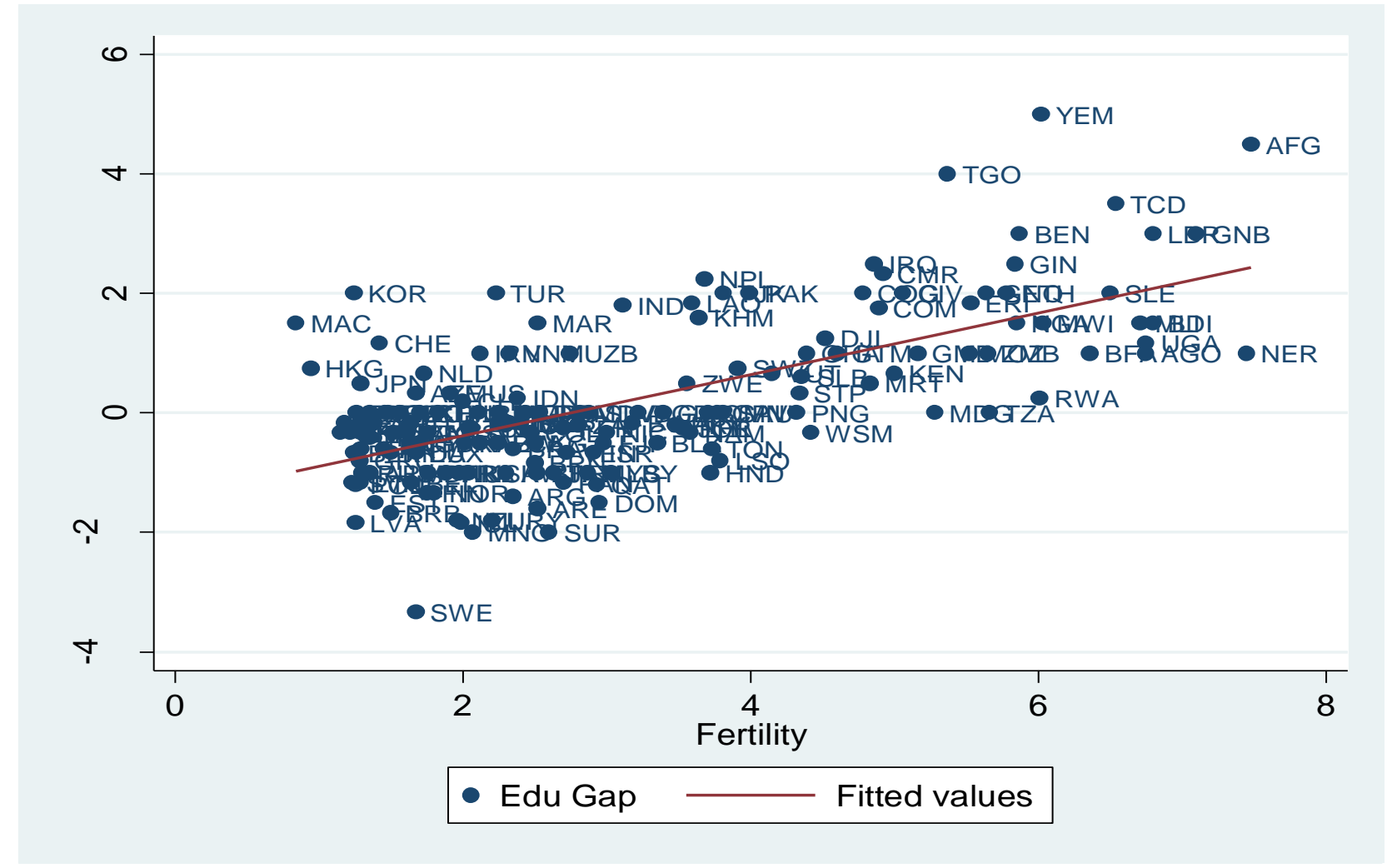

* Computed by authors based on cross-national data described in text. The education gap is measured by number of years, and fertility by the number of children. 
Figure 6: A Comparison of Fertility Rates Over Time

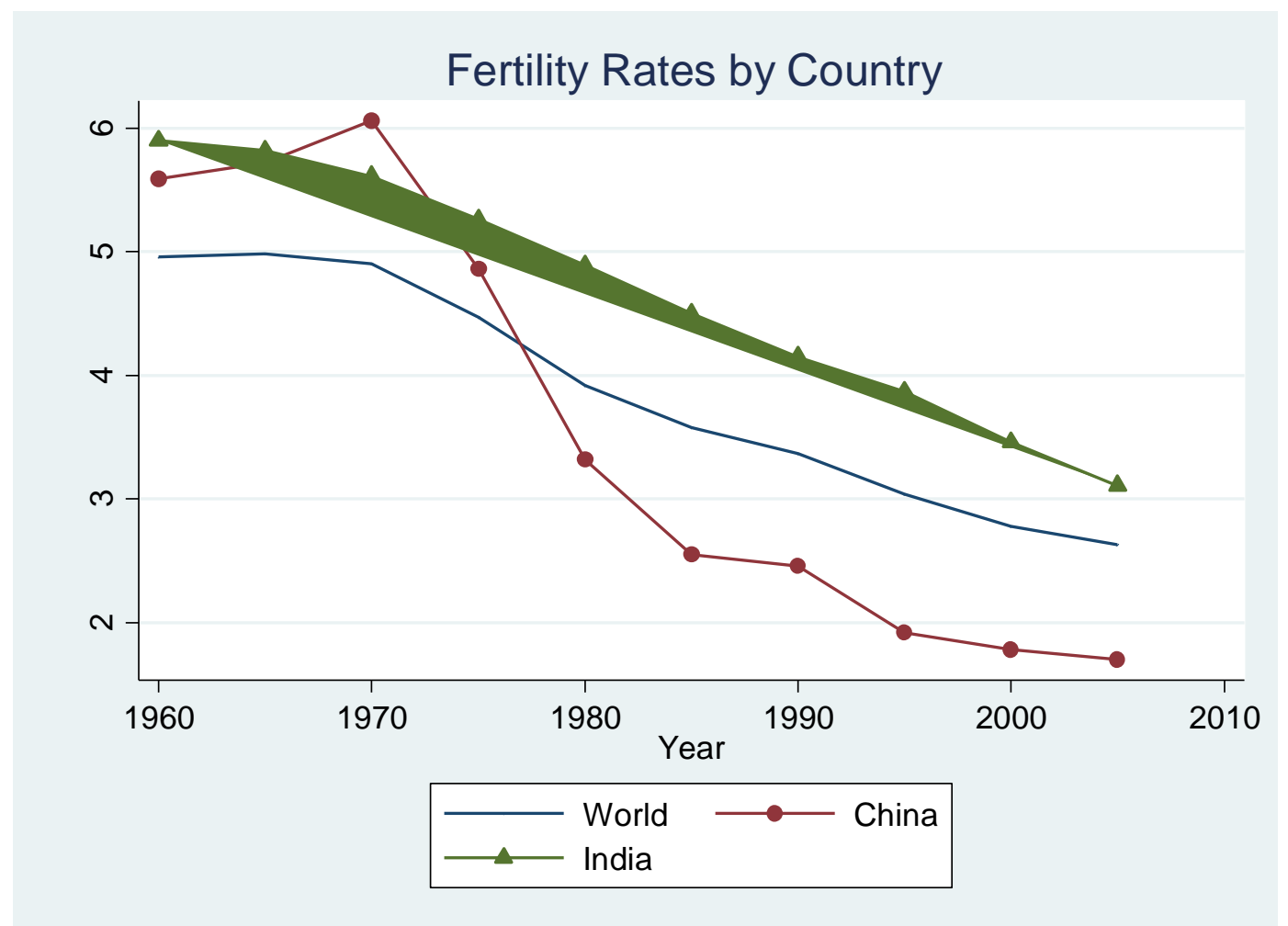

Source: http://www.wri.org/ and http://data.un.org/Explorer.aspx?d=CLINO. 


\section{Figure 7*}

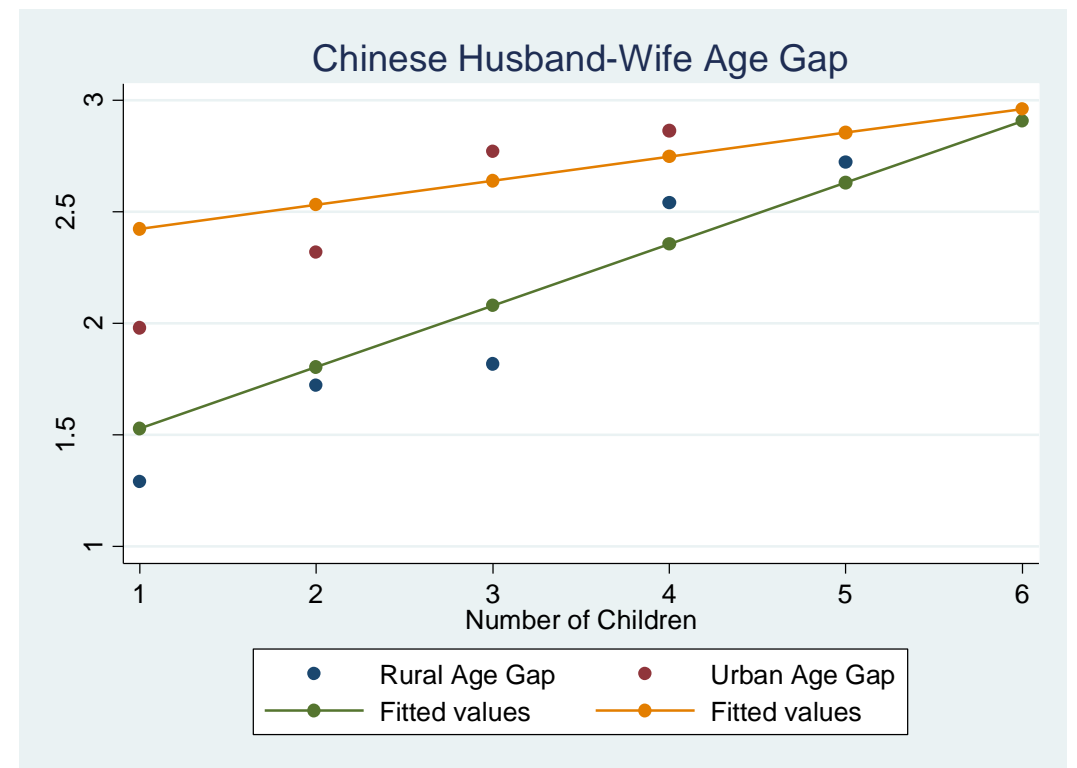

*Computed by authors based on 1993 China Health and Nutrition Survey

Figure 8*

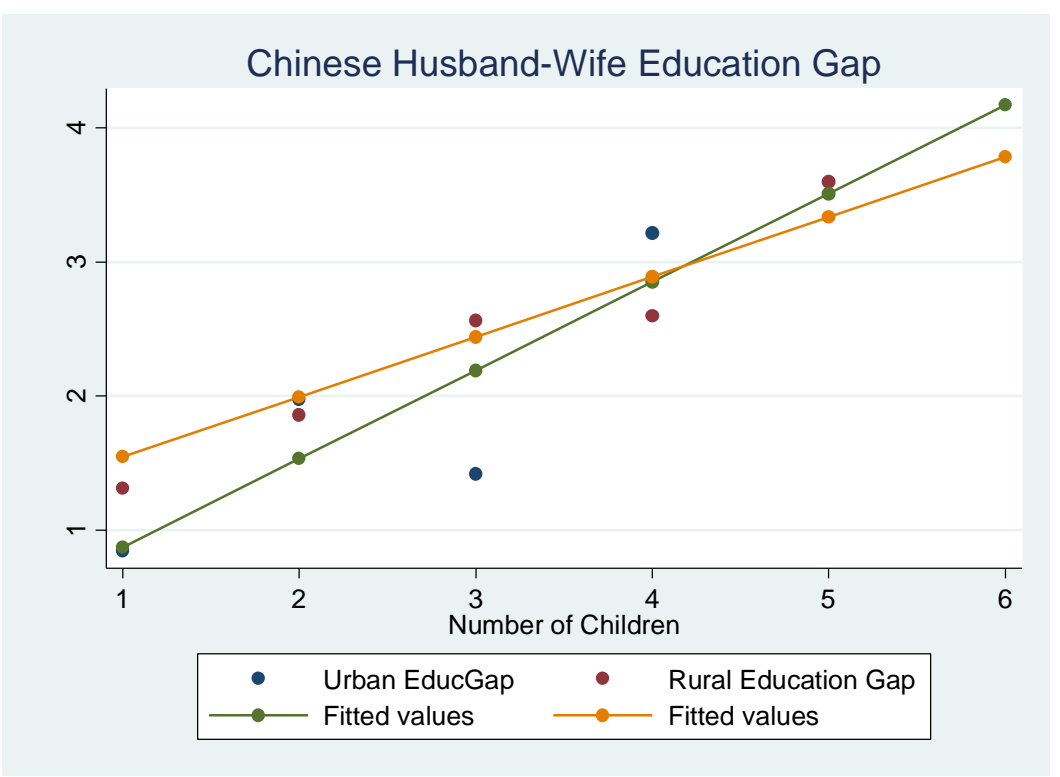

*Computed by authors based on 1993 China Health and Nutrition Survey 
Table 1

Women's Payoff Matrix

\begin{tabular}{|l|c|c|c|c|}
\hline \multicolumn{1}{|c|}{ Wife } & $\begin{array}{l}\text { High } \\
\text { intelligence } \\
\text { young women }\end{array}$ & $\begin{array}{l}\text { Low intelligence } \\
\text { young women }\end{array}$ & $\begin{array}{l}\text { High educated } \\
\text { old women } \\
\text { wusband }\end{array}$ & $\begin{array}{l}\text { Low educated } \\
\text { old women } \\
\text { young men }\end{array}$ \\
\hline $\begin{array}{l}\text { Low intelligence } \\
\text { young men }\end{array}$ & $k(1+\beta) y$ & $k(1+\beta) y$ & $y$ & $y$ \\
\hline $\begin{array}{l}\text { High educated old } \\
\text { men }\end{array}$ & $k y r$ & $k y r$ & $y r$ & $y r$ \\
\hline $\begin{array}{l}\text { Low educated old } \\
\text { men }\end{array}$ & $k y$ & $k y$ & $y$ & $y$ \\
\hline
\end{tabular}

Table 2

Men's Payoff Matrix

\begin{tabular}{|c|c|c|c|c|}
\hline Wife & $\begin{array}{l}\text { High } \\
\text { intelligence } \\
\text { young men }\end{array}$ & $\begin{array}{l}\text { Low } \\
\text { intelligence } \\
\text { young men }\end{array}$ & $\begin{array}{l}\text { High educated } \\
\text { old men }\end{array}$ & $\begin{array}{l}\text { Low educated } \\
\text { old men }\end{array}$ \\
\hline $\begin{array}{l}\text { High intelligence } \\
\text { young women }\end{array}$ & $k(1+\beta) x$ & $k(1+\beta) x$ & $\frac{k}{e} x$ & $k x$ \\
\hline $\begin{array}{l}\text { Low intelligence } \\
\text { young women }\end{array}$ & $k(1+\beta) x$ & $k(1+\beta) x$ & $\frac{k}{e} x$ & $k x$ \\
\hline $\begin{array}{l}\text { high educated } \\
\text { old women }\end{array}$ & $x r$ & $x r$ & $x r$ & $x r$ \\
\hline $\begin{array}{l}\text { Low educated } \\
\text { old women }\end{array}$ & $x$ & $x$ & $x$ & $x$ \\
\hline
\end{tabular}


Table 3

Husband-Wife Age Gap at First Marriage and Male-Female Schooling differences

\begin{tabular}{|l|c|c|}
\hline \multicolumn{1}{|c|}{ Area } & $\begin{array}{c}\text { Difference } \\
\text { SMAM }\end{array}$ & $\begin{array}{c}\text { Difference } \\
\text { EDUC }\end{array}$ \\
\hline EASTERN AFRICA & 4.3 & 0.57 \\
MIDDLE AFRICA & 6 & 1.73 \\
NORTHERN AFRICA & 4.5 & 0.06 \\
SOUTHERN AFRICA & 3.3 & -0.15 \\
WESTERN AFRICA & 6.6 & 1.61 \\
EASTERN ASIA & 2.4 & 0.95 \\
SOUTH-CENTRAL ASIA & 3.7 & 1.23 \\
SOUTH-EASTERN ASIA & 2.4 & 0.125 \\
WESTERN ASIA & 3.5 & 0.153 \\
EASTERN EUROPE & 3.1 & -0.5 \\
NORTHERN EUROPE & 2.3 & -1.58 \\
SOUTHERN EUROPE & 3.3 & -0.52 \\
WESTERN EUROPE & 2.7 & -0.167 \\
CARIBBEAN & 2.9 & -0.6 \\
CENTRAL AMERICA & 2.5 & -0.29 \\
SOUTH AMERICA & 2.9 & -0.63 \\
NORTHERN AMERICA & 2.3 & -0.67 \\
AUSTRALIA-NEW ZEALAND & 2.2 & -1.07 \\
MELANESIA & 2.6 & 0.26 \\
MICRONESIA & 3.9 & $\mathrm{NA}$ \\
POLYNESIA & 3.2 & $\mathrm{NA}$ \\
\hline
\end{tabular}

NA denotes unavailable data.

Computed from data contained in:

http://www.un.org/esa/population/publications/worldmarriage/WorldMarriagePatterns2000Table.xls

http://earthtrends.wri.org/searchable db/results.php?years=all\&variable ID=1117\&theme=4\&country ID=all\&country clas http://earthtrends.wri.org/searchable db/results.php?years=all\&variable ID =1116\&theme=4\&country ID=all\&country cla 
Descriptive Statistics*

\begin{tabular}{|c|c|c|}
\hline Variable & Rural & Urban \\
\hline Husband's Education & $\begin{array}{c}7.37 \\
(0.08)\end{array}$ & $\begin{array}{c}8.92 \\
(0.15)\end{array}$ \\
\hline Wife's Education & $\begin{array}{c}5.34 \\
(0.10)\end{array}$ & $\begin{array}{c}7.50 \\
(0.16)\end{array}$ \\
\hline Husband-Wife Education Gap & $\begin{array}{c}2.03 \\
(0.09)\end{array}$ & $\begin{array}{c}1.42 \\
(0.13)\end{array}$ \\
\hline Fertility & $\begin{array}{c}2.35 \\
(0.03)\end{array}$ & $\begin{array}{c}1.75 \\
(0.04)\end{array}$ \\
\hline More Than One Child & $\begin{array}{c}0.76 \\
(0.42)\end{array}$ & $\begin{array}{c}0.50 \\
(0.50)\end{array}$ \\
\hline Husband's Age at Marriage & $\begin{array}{l}23.82 \\
(3.66)\end{array}$ & $\begin{array}{l}25.14 \\
(3.66)\end{array}$ \\
\hline Wife's Age at Marriage & $\begin{array}{l}22.09 \\
(2.78)\end{array}$ & $\begin{array}{l}22.91 \\
(2.86)\end{array}$ \\
\hline Age Gap & $\begin{array}{c}1.76 \\
-0.07\end{array}$ & $\begin{array}{r}2.23 \\
-0.13\end{array}$ \\
\hline Number of Observations & 1644 & 624 \\
\hline $\begin{array}{l}\text { Fine if first child without } \\
\text { permission }\end{array}$ & $\begin{array}{c}1075.41 \\
(1629.41)\end{array}$ & $\begin{array}{c}1798.12 \\
(1785.53)\end{array}$ \\
\hline Number of Observations & 1454 & 506 \\
\hline Fine for one extra child & $\begin{array}{c}3137.96 \\
(2409.37)\end{array}$ & $\begin{array}{c}4405.16 \\
(2355.46)\end{array}$ \\
\hline Number of Observations & 1321 & 488 \\
\hline Gets Housing subsidy & $\begin{array}{c}0.10 \\
(0.30)\end{array}$ & $\begin{array}{c}0.27 \\
(0.44)\end{array}$ \\
\hline Number of Observations & 1423 & 519 \\
\hline
\end{tabular}

* Source: 1993 China Health and Nutrition Survey (CHNS). Age and education measured in years. Fertility measured as births per woman. Fines measured in yuan. Standard deviation of data given in parentheses. 
Table 5

Descriptive Statistics by Year and Location*

\begin{tabular}{|c|c|c|c|c|c|c|c|c|c|}
\hline \multirow[b]{2}{*}{ Variable } & \multicolumn{3}{|c|}{ Pre-1979 } & \multicolumn{3}{|c|}{ 1979-1985 } & \multicolumn{3}{|c|}{ Post-1985 } \\
\hline & Rural & Urban & Total & Rural & Urban & Total & Rural & Urban & Total \\
\hline Husband's Education & 6.22 & 7.97 & 6.66 & 8.18 & 9.56 & 8.59 & 8.72 & 9.68 & 9.01 \\
\hline Wife's Education & 3.61 & 5.63 & 4.12 & 6.61 & 8.64 & 7.21 & 7.3 & 9.21 & 7.86 \\
\hline Husband-Wife Education Gap & 2.6 & 2.35 & 2.54 & 1.88 & 0.92 & 1.38 & 1.43 & 0.48 & 1.14 \\
\hline Fertility & 2.97 & 2.34 & 2.81 & 1.99 & 1.42 & 1.83 & 1.47 & 1.18 & 1.39 \\
\hline Husband's Age at Marriage & 23.78 & 24.73 & 24.02 & 24.47 & 26.01 & 24.92 & 23.03 & 24.66 & 23.51 \\
\hline Wife's Age at Marriage & 21.55 & 22.15 & 21.70 & 22.85 & 24.04 & 23.2 & 22.22 & 22.70 & 22.36 \\
\hline Age Gap & 2.27 & 2.59 & 2.36 & 1.6 & 1.97 & 1.71 & 0.87 & 1.96 & 1.19 \\
\hline Number of Observations & 784 & 265 & 1049 & 499 & 208 & 707 & 361 & 151 & 512 \\
\hline
\end{tabular}

* Source 1993 China Health and Nutrition Survey (CHNS). Age and education data measured in years; fertility data measured as births per woman. 
Table 6

The Impact of China's One-Child Law

On Fertility and Husband-Wife Age and Education Differences

1993 CHNS Data

\begin{tabular}{|c|c|c|c|c|c|c|c|c|}
\hline & Fertility & Fertility & Fertility & Fertility & Mor_One & Mor_One & Mor_One & Mor_One \\
\hline Pre-Law & $\begin{array}{c}0.962^{\star * *} \\
(0.06)\end{array}$ & $\begin{array}{c}0.737^{\star \star *} \\
(0.06)\end{array}$ & $\begin{array}{l}0.835 \\
(0.11)\end{array}$ & $\begin{array}{c}0.751^{* * *} \\
(0.05)\end{array}$ & $\begin{array}{c}0.296^{\star \star *} \\
(0.03)\end{array}$ & $\begin{array}{c}0.224^{* * *} \\
(0.03)\end{array}$ & $\begin{array}{c}0.350^{* * *} \\
(0.08)\end{array}$ & $\begin{array}{c}0.342^{* * *} \\
(0.03)\end{array}$ \\
\hline Post-Law & $\begin{array}{c}-0.217^{\star *} \\
(0.07)\end{array}$ & $\begin{array}{c}-0.234^{\star \star \star} \\
(0.07)\end{array}$ & $\begin{array}{c}-0.847^{* * *} \\
(0.15)\end{array}$ & $\begin{array}{c}-0.292^{\star * *} \\
(0.07)\end{array}$ & $\begin{array}{c}-0.207^{\star \star \star} \\
(0.04)\end{array}$ & $\begin{array}{c}-0.227^{\star \star *} \\
(0.04)\end{array}$ & $\begin{array}{c}-0.773^{\star \star *} \\
(0.08)\end{array}$ & $\begin{array}{c}-0.356^{* * *} \\
(0.04)\end{array}$ \\
\hline Rural & $\begin{array}{c}0.608^{\star * *} \\
(0.11)\end{array}$ & $\begin{array}{c}0.422^{* * *} \\
(0.10)\end{array}$ & $\begin{array}{c}0.462^{\star \star *} \\
(0.10)\end{array}$ & $\begin{array}{c}0.69^{\star * *} \\
(0.04)\end{array}$ & $\begin{array}{c}0.306^{\star * *} \\
(0.05)\end{array}$ & $\begin{array}{c}0.222^{\star \star *} \\
(0.04)\end{array}$ & $\begin{array}{c}0.245^{\star \star \star} \\
(0.04)\end{array}$ & $\begin{array}{c}0.704^{\star * *} \\
(0.01)\end{array}$ \\
\hline Rural*Post-Law & $\begin{array}{c}-0.313^{* * *} \\
(0.09) \\
\end{array}$ & $\begin{array}{c}-0.307^{* * *} \\
(0.09)\end{array}$ & $\begin{array}{c}-0.238^{* * *} \\
(0.09)\end{array}$ & $\begin{array}{c}-0.302^{* * *} \\
(0.09)\end{array}$ & $\begin{array}{c}-0.0788 \\
(0.05) \\
\end{array}$ & $\begin{array}{c}-0.0664 \\
(0.05) \\
\end{array}$ & $\begin{array}{c}-0.0259 \\
(0.05) \\
\end{array}$ & $\begin{array}{c}-0.189^{* *} \\
(0.05)\end{array}$ \\
\hline Exogenous X & No & Yes & Yes & Yes & No & Yes & Yes & Yes \\
\hline Year Dummies & No & No & Yes & No & No & No & Yes & No \\
\hline Community Dummies & No & No & No & Yes & No & No & No & Yes \\
\hline R-squared & 0.312 & 0.367 & 0.489 & 0.561 & 0.2382 & 0.2819 & 0.3152 & 0.4912 \\
\hline
\end{tabular}

\begin{tabular}{|c|c|c|c|c|c|c|c|c|}
\hline & Agegap & Agegap & Agegap & Agegap & Edugap & Edugap & Edugap & Edugap \\
\hline Pre-Law & $\begin{array}{c}0.650^{\star \star \star} \\
(0.17)\end{array}$ & $\begin{array}{c}0.568^{\star \star \star} \\
(0.18)\end{array}$ & $\begin{array}{c}11.48^{\star \star *} \\
(0.36)\end{array}$ & $\begin{array}{c}0.338^{\star \star} \\
(0.17)\end{array}$ & $\begin{array}{c}1.142^{\star \star *} \\
(0.18)\end{array}$ & $\begin{array}{c}1.063^{\star \star \star} \\
(0.19)\end{array}$ & $\begin{array}{c}10.20^{\star \star *} \\
(0.49)\end{array}$ & $\begin{array}{c}0.810^{\star \star \star} \\
(0.20)\end{array}$ \\
\hline Post-Law & $\begin{array}{c}0.0164 \\
(0.29)\end{array}$ & $\begin{array}{c}0.00271 \\
(0.30)\end{array}$ & $\begin{array}{c}0.0346 \\
(0.66)\end{array}$ & $\begin{array}{l}0.213 \\
(0.34)\end{array}$ & $\begin{array}{c}-0.602^{*} \\
(0.32)\end{array}$ & $\begin{array}{c}-0.705^{\star \star \star} \\
(0.33)\end{array}$ & $\begin{array}{c}-3.661^{* * *} \\
(0.91)\end{array}$ & $\begin{array}{c}-0.455^{\star} \\
(0.28)\end{array}$ \\
\hline Rural & $\begin{array}{l}-0.337 \\
(0.24)\end{array}$ & $\begin{array}{c}-0.418^{\star \star *} \\
(0.18)\end{array}$ & $\begin{array}{c}-0.448^{\star *} \\
(0.25)\end{array}$ & $\begin{array}{c}-0.0837 \\
(0.12)\end{array}$ & $\begin{array}{l}0.425^{*} \\
(0.26)\end{array}$ & $\begin{array}{l}0.314 \\
(0.26)\end{array}$ & $\begin{array}{l}0.334 \\
(0.26)\end{array}$ & $\begin{array}{c}4.007^{\star \star \star} \\
(0.03)\end{array}$ \\
\hline RuralPost-Law & $\begin{array}{c}-0.764^{* *} \\
(0.34)\end{array}$ & $\begin{array}{c}-0.718^{\star *} \\
(0.30)\end{array}$ & $\begin{array}{c}-0.704^{* *} \\
(0.34)\end{array}$ & $\begin{array}{c}-0.736^{*} \\
(0.39)\end{array}$ & $\begin{array}{l}0.522 \\
(0.40)\end{array}$ & $\begin{array}{l}0.482 \\
(0.40)\end{array}$ & $\begin{array}{l}0.537 \\
(0.41)\end{array}$ & $\begin{array}{l}0.093 \\
(0.36)\end{array}$ \\
\hline $\begin{array}{l}\text { Exogenous } \mathrm{X} \\
\text { Year Dummies } \\
\text { Community Dummies }\end{array}$ & $\begin{array}{l}\text { No } \\
\text { No } \\
\text { No }\end{array}$ & $\begin{array}{l}\text { Yes } \\
\text { No } \\
\text { No }\end{array}$ & $\begin{array}{l}\text { Yes } \\
\text { Yes } \\
\text { No }\end{array}$ & $\begin{array}{l}\text { Yes } \\
\text { No } \\
\text { Yes }\end{array}$ & $\begin{array}{l}\text { No } \\
\text { No } \\
\text { No }\end{array}$ & $\begin{array}{l}\text { Yes } \\
\text { No } \\
\text { No }\end{array}$ & $\begin{array}{l}\text { Yes } \\
\text { Yes } \\
\text { No }\end{array}$ & $\begin{array}{l}\text { Yes } \\
\text { No } \\
\text { Yes }\end{array}$ \\
\hline R-squared & 0.031 & 0.036 & 0.074 & 0.208 & 0.035 & 0.043 & 0.069 & 0.216 \\
\hline
\end{tabular}

Location clustered robust standard errors in parentheses; nobs $=2268 ;{ }^{* * *} p<0.01,{ }^{* \star} p<0.05,{ }^{*} p<0.1$

Pseudo R2 reported for probit regressions

$\mathrm{dF} / \mathrm{dx}$ is for discrete change of dummy variable from 0 to 1

$z$ and $p>|z|$ correspond to the test of the underlying coefficient being 0

Dependent Variables: Fertility=number of children; Mor_One=whether more than one child;

Agegap=husband age minus wife age; Edugap = husband education minus wife education 
Table 7

The Impact of the One-Child Law on Husband-Wife Educational Differences

\begin{tabular}{|c|c|c|c|c|c|c|c|c|}
\hline \multirow[b]{2}{*}{ VARIABLES } & \multicolumn{4}{|c|}{$2000 \mathrm{CHNS}$} & \multicolumn{4}{|c|}{2004 CHNS } \\
\hline & Edugap & Edugap & Edugap & Edugap & Edugap & Edugap & Edugap & Edugap \\
\hline \multirow[t]{2}{*}{ Pre-Law } & $1.143^{* \star *}$ & $0.875^{\star \star \star}$ & 1.593 & 0.274 & $1.130^{\star \star *}$ & $1.012^{* \star \star}$ & -1.538 & $0.528^{*}$ \\
\hline & $(0.21)$ & $(0.25)$ & (3.29) & $(0.27)$ & $(0.30)$ & $(0.31)$ & $(3.25)$ & $(0.31)$ \\
\hline \multirow[t]{2}{*}{ Post-Law } & -0.415 & -0.0341 & -0.675 & 0.434 & $-0.840^{\star \star *}$ & -0.471 & $-2.005^{\star \star \star}$ & -0.216 \\
\hline & $(0.29)$ & $(0.34)$ & $(1.71)$ & $(0.37)$ & $(0.24)$ & $(0.29)$ & $(0.57)$ & $(0.29)$ \\
\hline \multirow[t]{2}{*}{ Rural } & $0.749^{\star \star \star}$ & $0.772^{\star * *}$ & $0.671^{* * *}$ & 2.373 & $0.760^{* * *}$ & $0.777^{* \star *}$ & $0.628^{* \star *}$ & $10.12^{* *}$ \\
\hline & $(0.20)$ & $(0.20)$ & $(0.20)$ & $(4.36)$ & $(0.23)$ & $(0.23)$ & $(0.23)$ & $(4.25)$ \\
\hline \multirow[t]{2}{*}{ RuralPost-Law } & -0.327 & -0.308 & -0.353 & -0.447 & -0.227 & -0.212 & -0.128 & -0.292 \\
\hline & $(0.34)$ & $(0.34)$ & $(0.35)$ & $(0.38)$ & $(0.29)$ & $(0.29)$ & $(0.29)$ & $(0.30)$ \\
\hline Controls & No & Yes & Yes & Yes & No & Yes & Yes & Yes \\
\hline Location Dummies & No & No & No & Yes & No & No & No & Yes \\
\hline Year Dummies & No & No & Yes & No & No & No & Yes & No \\
\hline Observations & 1901 & 1901 & 1898 & 1901 & 2352 & 2352 & 2348 & 2352 \\
\hline R-squared & 0.042 & 0.045 & 0.071 & 0.272 & 0.044 & 0.046 & 0.067 & 0.27 \\
\hline
\end{tabular}

Standard errors in parentheses; ${ }^{\star \star *} p<0.01,{ }^{* *} p<0.05,{ }^{*} p<0.1$

Dependent Variable: Edugap= husband's education minus wife's education

Table 8

\begin{tabular}{|c|c|c|c|c|c|c|}
\hline \multicolumn{7}{|c|}{ Fines and Subsidies as a Function of Pre-Law Fertility } \\
\hline \multicolumn{7}{|c|}{1993 CHNS Data } \\
\hline & \multicolumn{3}{|c|}{ Rural Residencies } & \multicolumn{3}{|c|}{ Urban Residencies } \\
\hline VARIABLES & F1 & F2 & $\mathrm{s}$ & F1 & F2 & $\mathbf{s}$ \\
\hline \multirow[t]{2}{*}{ Pre-Law Fertility } & 0.587 & -1.146 & -0.168 & -0.0517 & -0.350 & -0.354 \\
\hline & $(1.207)$ & $(0.807)$ & $(0.233)$ & $(0.616)$ & $(0.314)$ & $(0.215)$ \\
\hline \multirow[t]{2}{*}{ Constant } & $5.862^{\star \star *}$ & $8.845^{\star \star *}$ & 0.271 & $6.996^{\star * *}$ & $8.490^{\star \star \star}$ & $0.520^{\star * *}$ \\
\hline & $(1.155)$ & $(0.780)$ & $(0.221)$ & $(0.513)$ & $(0.259)$ & $(0.173)$ \\
\hline Number of Communities & 86 & 98 & 106 & 39 & 39 & 43 \\
\hline R-squared & 0.003 & 0.021 & 0.005 & 0.000 & 0.033 & 0.062 \\
\hline \multicolumn{7}{|c|}{ Dependent Variables: F1: In(fine if first birth without permission); } \\
\hline \multicolumn{7}{|c|}{ F2: In(fine for one extra child); and S: Whether community provides } \\
\hline \multicolumn{7}{|c|}{ better house or adherents to the law } \\
\hline \multicolumn{7}{|c|}{ Standard errors in parentheses; $* * * p<0.01, * * p<0.05, * p<0.1$} \\
\hline
\end{tabular}


Table 9

The Impact of One-Child Law fines and Subsidies on Fertility and Husband-Wife Age and Educational Differences 1993 Proprietary Data

\begin{tabular}{|c|c|c|c|c|c|c|c|c|c|c|c|c|}
\hline VARIABLES & Fertility & Fertility & Fertility & Fertility & Agegap & Agegap & Agegap & Agegap & Edugap & Edugap & Edugap & Edugap \\
\hline \multirow[t]{2}{*}{ Rural } & $0.853^{* * *}$ & $0.516^{* * *}$ & $0.609^{* * *}$ & $0.473^{* * *}$ & -0.442 & $-0.607^{*}$ & $-0.602 * *$ & $-0.668^{* *}$ & 0.528 & 0.394 & 0.283 & 0.163 \\
\hline & $(0.130)$ & (0.109) & $(0.121)$ & $(0.118)$ & $(0.294)$ & (0.318) & $(0.302)$ & (0.319) & $(0.327)$ & $(0.332)$ & $(0.343)$ & $(0.345)$ \\
\hline \multirow[t]{2}{*}{ Post Law*Rural } & $-1.144^{* * *}$ & $-0.947^{* * *}$ & -0.159 & -0.165 & $-1.159 * * *$ & $-1.039 * * *$ & $-0.870^{*}$ & $-0.824 *$ & $-0.676^{* *}$ & $-0.764^{* *}$ & 0.744 & 0.675 \\
\hline & $(0.0707)$ & $(0.0717)$ & $(0.114)$ & $(0.114)$ & $(0.184)$ & $(0.180)$ & $(0.464)$ & $(0.469)$ & $(0.314)$ & $(0.313)$ & $(0.516)$ & $(0.522)$ \\
\hline \multirow[t]{2}{*}{ In(fines) } & $-0.258^{* * *}$ & $-0.185^{* * *}$ & $-0.235^{* * *}$ & $-0.209 * * *$ & $-0.332^{* * *}$ & $-0.315^{* *}$ & $-0.299 * *$ & $-0.301 * *$ & $-0.459 * * *$ & $-0.477^{* * *}$ & $-0.409 * *$ & $-0.424^{* *}$ \\
\hline & $(0.0731)$ & $(0.0536)$ & $(0.0589)$ & $(0.0529)$ & $(0.126)$ & $(0.129)$ & $(0.132)$ & $(0.131)$ & $(0.168)$ & $(0.170)$ & $(0.168)$ & (0.169) \\
\hline \multirow[t]{2}{*}{ Housing Subsidy } & $-0.372 * * *$ & $-0.235^{* * *}$ & $-0.312^{* * *}$ & $-0.252^{* * *}$ & 0.285 & 0.348 & 0.376 & 0.393 & -0.514 & -0.481 & -0.512 & -0.494 \\
\hline & $(0.118)$ & $(0.0862)$ & $(0.0908)$ & $(0.0739)$ & $(0.336)$ & $(0.340)$ & $(0.344)$ & $(0.345)$ & $(0.363)$ & $(0.353)$ & $(0.354)$ & $(0.347)$ \\
\hline X Controls & No & Yes & No & Yes & No & Yes & No & Yes & No & Yes & No & Yes \\
\hline Year Dummies & No & No & Yes & Yes & No & No & Yes & Yes & No & No & Yes & Yes \\
\hline R-squared & 0.240 & 0.376 & 0.554 & 0.575 & 0.031 & 0.042 & 0.091 & 0.096 & 0.023 & 0.031 & 0.073 & 0.079 \\
\hline
\end{tabular}

Robust standard errors in parentheses; $\quad$ nobs $=1551 ;{ }^{* * *} p<0.01, * * p<0.05,{ }^{*} p<0.1$

Variables defined in text. 


\section{References}

Atkinson, Maxine and Becky Glass (1985) "Marital Age Heterogamy and Homogamy,

Becker, Gary S. (1973) “A Theory of Marriage: Part I," Journal of Political Economy 81(4): 813-846.

Becker, Gary S. (1985) "Human Capital, Effort, and the Sexual Division of Labor," Journal of Labor Economics 3: 33-38.

Becker, Gary S. (1991) A Treatise on the Family, (Cambridge, MA, Harvard University Press).

Bergstrom, Theodore and Bagnoli, Mark (1993) "Courtship as a Waiting Game," Journal of Political Economy 101(1):185-202.

Bertrand, Marianne, Claudia Goldin, and Lawrence Katz (2009) "Dynamics of the Gender Gap for Young Professionals in the Corporate and Financial Sectors," National Bureau of Economic Research, Inc, NBER Working Papers: 14681.

Burdett, Kenneth and Wright, Randall (1998) "Two-sided Search with Nontransferable Utility," Review of Economic Dynamics 1(1): 220-45.

Chiappori, Pierre-Andre, Murat Iyigun and Yoram Weiss $(2008,2010)$ "Investment in Schooling and the Marriage Market," Columbia University Working Paper.

Devereux, Paul and Robert A. Hart (2008) "Forced to Be Rich? Returns to Compulsory Schooling in Britain," Discussion Paper No. 3305.

DiPrete, Thomas and Claudia Buchmann, Claudia (2006) "Gender-Specific Trends in the Value of Education and the Emerging Gender Gap in College Completion," Demography, 43(1): 1-24.

Ebenstein, Avraham (2010) "The 'Missing Girls' of China and the Unintended Consequences of the One Child Policy," Journal of Human Resources 45(1): 87-115.

Gale, David and Shapley, Lloyd (1962) "College Admission and the Stability of Marriage," American Mathematical Monthly 69(1): 9-15.

Giolito, Eugenio P. (2003) "A Search Model of Marriage with Differential Fecundity," IZA Bonn Discussion Paper No.1082.

Goldin, Claudia (1990) Understanding the Gender Gap : An Economic History of American Women (New York : Oxford University Press).

Gustafsson, Siv and Adriaan Kalwij, eds. ( 2006), Education and Postponement of Maternity: Economic Analyses for Industrialized (Dordrecht: Springer, Kluwer 
Academic).

Hajnal, J. (1953) “Age at Marriage and Proportions Marrying," Journal of Population Studies 7: 115-136.

Harkness, Susan and Jane Waldfogel (2003) "The Family Gap in Pay: Evidence From Seven Industrialized Countries," Research in Labor Economics 22:369-413.

Hubbard, William H. J. (2011) "The Phantom Gender Difference in the College Wage Premium”, Journal of Human Resources 46(3):568-586.

Knodel, John (1988) Demographic Behavior in the Past: A Study of Fourteen German Village Populations in the Eighteenth and Nineteenth Centuries (Cambridge: Cambridge University Press.

Mare, Robert (1991) "Five Decades of Educational Assortative Mating," American Sociological Review 56: 15-32.

McElroy, Marjorie and Dennis Tao Yang (2000) "Carrots and Sticks: Fertility Effects of China's Population Policies,” The American Economic Review 90(2): 389-392.

Mortensen, Dale (1988) "Matching: Finding a Partner for Life or Otherwise," American Journal of Sociology 94:215-40

Munich, Daniel, Jan Svejnar, and Katherine Terrell (2005) "Is Women's Human Capital Valued More by Markets Than by Planners?," Journal of Comparative Economics, 33(2): 278-99.

Pissarides, Christopher (1990) Equilibrium Unemployment Theory (Cambridge, Mass. and Oxford: Blackwell).

Polachek, Solomon (1975) "Potential Biases in Measuring Male-Female Discrimination," Journal of Human Resources 10(2): 205-29.

Poppel, Frans Van, Aart C. Liefbroer, Jeroen K. Vermunt and Wilma Smeenk (2001). "Love, Necessity and Opportunity: Changing Patterns of Marital Age Homogamy in the Netherlands, 1850-1993," Population Studies, 55: 1-13.

Quisumbing, Agnes and Kelly Hallman (2005) "Marriage in transition: Evidence on age, education, and assets from six developing countries," in Jere Behrman, Barney Cohen, Cynthia B. Lloyd, Nelly Stromquist (eds). The Transition to Adulthood in Developing Countries: Selected Studies. Washington, DC: National Academies Press.

Rockwell, Richard (1976) "Historical Trends and Variations in Educational Homogamy," Journal of Marriage and the Family 38:83-96.

Rolf, Karen and Joseph Ferrie (2008) "The May-December Relationship Since 1850: Age Homogamy in the U.S." Paper presented at the Population Association of America Annual Convention, New Orleans. 
Shorter, Edward (1975) The Making of the Modern Family (New York: Basic Books).

Siow, Aloysius (1998) "Differential Fecundity, Markets, and Gender Roles," Journal of Political Economy 106(2): 334-354.

Soares Rodrigo and Bruno Falcão (2008) "The Demographic Transition and the Sexual Division of Labor,” Journal of Political Economy 116(6):1058-1104).

United Nations (1997) State of the World Population Report.

United Nations (2000) World Marriage Patterns.

Van Poppel, Frans, Aart Liefbroer, and Jeroen Vermunt (2001) "Love, Necessity and Opportunity: Changing Patterns of Marital Age Homogamy in the Netherlands, 1850-1993," Population Studies 55:1-13.

Veevers, Jean E. (1984) “Age-Discrepant Marriages: Cross-National Comparisons Of Canadian-American Trends," Social Biology 31(1-2): 18-27.

Vella, Frank and Sean Collins (1990) "The Value of Youth: Equalizing Age Differentials in Marriages," Applied Economics, 22(3): 359-73.

World Bank (2006) World Development Indicators, 2006.

Wu, Zheng (1998) "Recent Trends In Marriage Patterns In Canada Policy," Policy Options, 19(7), 3-6. 


\section{Appendix A}

Chinese Husband and Wife Age and Education Levels by Number of Children

\begin{tabular}{|c|c|c|c|c|}
\cline { 2 - 5 } \multicolumn{1}{c|}{} & \multicolumn{2}{c|}{ Age at Marriage } & \multicolumn{2}{c|}{ Education Level } \\
\hline Number of Children & Husband & Wife & Husband & Wife \\
\hline 1 & 24.9 & 23.3 & 9.4 & 8.3 \\
\hline 2 & 24.2 & 22.4 & 7.8 & 5.9 \\
\hline 3 & 23.9 & 21.8 & 6.7 & 4.3 \\
\hline 4 & 23.5 & 20.9 & 6 & 3.4 \\
\hline 5 & 22.5 & 19.8 & 5.5 & 1.9 \\
\hline 6 & 21.9 & 19.9 & 5.2 & 3.1 \\
\hline
\end{tabular}

Source: Computed from CHNS data. 


\section{Appendix B: The Model}

\section{A.1 The Population Composition}

Assume the meeting technology such that the number of contacts between single females $(\mathrm{F})$ and single males $(\mathrm{M})$ follows a constant return to scale meeting function developed by Pissarides (1990):

$$
\eta=\mu M^{\theta} F^{1-\theta}
$$

where $0<\theta<1$ and $\mu$ a positive constant, also less than 1 .

Also assume every non-married person will only meet at most one member of the opposite sex per period. The probability that a single person meets with a single member of the opposite sex per period depends on the relative availability in the pool of potential partners. From the above, the probability that a single woman meets a single man is

$$
p_{f}=\mu\left(\frac{M}{F}\right)^{\theta}=\frac{\eta}{F} .
$$

The probability that a single man meets with a single woman is

$$
p_{m}=\mu\left(\frac{M}{F}\right)^{\theta-1}=\frac{\eta}{M} .
$$

The composition of single men $(\boldsymbol{M})$ and women $(\mathbf{F})$ can be depicted as

$$
\begin{gathered}
M=m_{1, l}+m_{1, h}+m_{2, l}+m_{2, h} \\
F=f_{1, l}+f_{1, h}+f_{2, l}+f_{2, h}
\end{gathered}
$$

where the first subscript refers to age (1 or 2) and the second low (1) or high (h) ability for the young and low (l) or high (h) education for the old. Single men comprise low and high ability young men, and low and high educated old men. The same breakdown applies for women. The fractions of singles in each group are as follows:

$$
p_{m_{1, l}}=\frac{m_{1, l}}{M} \quad p_{m_{1, h}}=\frac{m_{1, h}}{M} \quad p_{m_{2, l}}=\frac{m_{2, l}}{M} \quad p_{m_{2, h}}=\frac{m_{2, h}}{M}
$$




$$
p_{f_{1, l}}=\frac{f_{1, l}}{F} \quad p_{f_{1, h}}=\frac{f_{1, h}}{F} \quad p_{f_{2, l}}=\frac{f_{2, l}}{F} \quad p_{f_{2, h}}=\frac{f_{2, h}}{F}
$$

\section{A.2 Utility of Marriage for Old Men (Age 2)}

The probabilities that a low and high ability young man receives a marriage offer from a low and high ability young woman are

$$
\begin{aligned}
p_{m_{1, l}}^{f_{1, l}} & =p_{m} p_{m_{1, l}} p_{f_{1, l}}\left(1-G_{m}\left(R_{f_{1, l}}^{m_{1, l}}\right)\right) \\
p_{m_{1, l}}^{f_{1, h}} & =p_{m} p_{m_{1, l}} p_{f_{1, h}}\left(1-G_{m}\left(R_{f_{1, h}}^{m_{1, l}}\right)\right) \\
p_{m_{1, h}}^{f_{1, l}} & =p_{m} p_{m_{1, h}} p_{f_{1, l}}\left(1-G_{m}\left(R_{f_{1, l}}^{m_{1, h}}\right)\right) \\
p_{m_{1, h}}^{f_{1, h}} & =p_{m} p_{m_{1, h}} p_{f_{1, h}}\left(1-G_{m}\left(R_{f_{1, h}}^{m_{1, h}}\right)\right)
\end{aligned}
$$

where $R_{f_{i, j}}^{m_{i, j}} \quad(\mathrm{i}=1,2$ and $\mathrm{j}=1, \mathrm{~h})$ is the reservation value that a woman $(\mathrm{i}, \mathrm{j})$ sets for a $\operatorname{man}(\mathrm{i}, \mathrm{j})$.

The probabilities that an old low-educated man and an old high-educated man receive a marriage offer from a young woman are

$$
\begin{aligned}
p_{m_{2, l}}^{f_{1, l}} & =p_{m} p_{m_{2, l}} p_{f_{1, l}}\left(1-G_{m}\left(R_{f_{1, l}}^{m_{2, l}}\right)\right) \\
p_{m_{2, l}}^{f_{1, h}} & =p_{m} p_{m_{2, l}} p_{f_{1, h}}\left(1-G_{m}\left(R_{f_{1, h}}^{m_{2, l}}\right)\right) \\
p_{m_{2, h}}^{f_{1, l}} & =p_{m} p_{m_{2, h}} p_{f_{1, l}}\left(1-G_{m}\left(R_{f_{1, l}}^{m_{2, h}}\right)\right) \\
p_{m_{2, h}}^{f_{1, h}} & =p_{m} p_{m_{2, h}} p_{f_{1, h}}\left(1-G_{m}\left(R_{f_{1, h}}^{m_{2, h}}\right)\right) .
\end{aligned}
$$

Since old women prefer accepting all potential proposals to dying single, old women will accept any proposal they receive. Therefore, the probabilities that a young man with high or low ability and an old man (low or high-educated) receives a marriage offer from an old low or high-educated woman are respectively

$$
\begin{aligned}
& p_{m_{1, l}}^{f_{2, l}}=p_{m} p_{m_{1, l}} p_{f_{2, l}} \\
& p_{m_{1, l}}^{f_{2, h}}=p_{m} p_{m_{1, l}} p_{f_{2, h}}
\end{aligned}
$$


$p_{m_{1, h}}^{f_{2, l}}=p_{m} p_{m_{1, h}} p_{f_{2, l}}$

$p_{m_{1, h}}^{f_{2, h}}=p_{m} p_{m_{1, h}} p_{f_{2, h}}$

$p_{m_{2, l}}^{f_{2, l}}=p_{m} p_{m_{2, l}} p_{f_{2, l}}$

$p_{m_{2, l}}^{f_{2, h}}=p_{m} p_{m_{2, l}} p_{f_{2, h}}$

$p_{m_{2, h}}^{f_{2, l}}=p_{m} p_{m_{2, h}} p_{f_{2, l}}$

$p_{m_{2, h}}^{f_{2, h}}=p_{m} p_{m_{2, h}} p_{f_{2, h}}$

Based on these probabilities and the values given in the payoff matrices, the utility of marriage for an old low-educated man is

$$
U_{m_{2, l}}=\left(p_{m_{2, l}}^{f_{1, l}} k+p_{m_{2, l}}^{f_{1, h}} k+p_{m_{2, l}}^{f_{2, l}}+p_{m_{2, l}}^{f_{2, h}} r\right) \bar{x} .
$$

The utility of marriage for an old high-educated man is

$$
U_{m_{2, h}}=\left(p_{m_{2, h}}^{f_{1, l}} \frac{k}{e}+p_{m_{2, h}}^{f_{1, h}} \frac{k}{e}+p_{m_{2, h}}^{f_{2, l}}+p_{m_{2, h}}^{f_{2, h}} r\right) \bar{x} .
$$

\section{A.3 Utility of Marriage for Young Men}

The utility of marriage for a young man with low ability or high ability comes from the utility that this young man marries a young woman with low ability or high ability, an old low-educated woman and an old high-educated woman, that is

$$
\begin{aligned}
& U_{m_{1, l}}=p_{m_{1, l}}^{f_{1, l}}(1+\beta) k \int_{R_{m_{1, l}}}^{1} f_{1, l} x d x+p_{m_{1, l}}^{f_{1, h}}(1+\beta) k \int_{R_{m, l}^{f}}^{1} x d x+p_{m_{1, l}}^{f_{2, l}} \int_{R_{m_{1, l}}}^{1} x d x+p_{m_{1, l}}^{f_{2, h}} \int_{R_{m_{1}, l}^{f_{2, l}}}^{1} x d x \\
& U_{m_{1, h}}=p_{m_{1, h}}^{f_{1, l}}(1+\beta) k \int_{R_{m, h}^{f_{1}, l}}^{1} x d x+p_{m_{1, h}}^{f_{1, h}}(1+\beta) k \int_{R_{m, h}^{f, h}}^{1} x d x+p_{m_{1, h}}^{f_{2, l}} \int_{R_{m_{1}, h} f_{1, l}}^{1} x d x+p_{m_{1, h}}^{f_{2, h}} r \int_{R_{m, h}^{f_{2}, h}}^{1} x d x
\end{aligned}
$$

\section{A.4 Optimization Problem for Young Men}

A young man maximizes his total discounted utility by choosing the optimal reservation value that he sets for a young woman and an old woman. Thus, the optimization problems for low and high ability young men are 


$$
\begin{aligned}
& V_{m_{1, l}}=\max U_{m_{1, l}}+\left(1-\gamma_{m_{1, l}}\right) \beta U_{m_{2, l}} \\
& \gamma_{m_{1, l}}=p_{m_{1, l}}^{f_{1, l}}\left(1-G_{f}\left(R_{m_{1, l}}^{f_{1, l}}\right)\right)+p_{m_{1, l}}^{f_{1, h}}\left(1-G_{f}\left(R_{m_{1, l}}^{f_{1, l}}\right)\right)+p_{m_{1, l}}^{f_{2, l}}\left(1-G_{f}\left(R_{m_{1, l}}^{f_{2, h}}\right)\right)+p_{m_{1, l}}^{f_{2, l}}\left(1-G_{f}\left(R_{m_{1, l}}^{f_{2, h}}\right)\right)
\end{aligned}
$$

and

$V_{m_{1, h}}=\max U_{m_{1, h}}+\left(1-\gamma_{m_{1, h}}\right) \beta U_{m_{2, h}}$

$\gamma_{m_{1, h}}=p_{m_{1, h}}^{f_{1, l}}\left(1-G_{f}\left(R_{m_{1, h}}^{f_{1, l}}\right)\right)+p_{m_{1, h}}^{f_{1, h}}\left(1-G_{f}\left(R_{m_{1, h}}^{f_{1, h}}\right)\right)+p_{m_{1, h}}^{f_{2, l}}\left(1-G_{f}\left(R_{m_{1, h}}^{f_{2, l}}\right)\right)+p_{m_{1, h}}^{f_{2, h}}\left(1-G_{f}\left(R_{m_{1, h}}^{f_{2, h}}\right)\right)$

where $\gamma_{m_{1, l}}$ and $\gamma_{m_{1, h}}$ are the probabilities that a young low ability man and a young high ability man get married at age 1 .

\section{A.5 The Utility of Marriage for Old Women}

Similarly, the probabilities that a young low or high ability woman and an old low-educated or high-educated woman receives a marriage offer from a young low or high ability man are respectively

$$
\begin{aligned}
& p_{f_{1, l}}^{m_{1, l}}=p_{f} p_{f_{1, l}} p_{m_{1, l}}\left(1-G_{f}\left(R_{m_{1, l}}^{f_{1, l}}\right)\right) \\
& p_{f_{1, l}}^{m_{1, h}}=p_{f} p_{f_{1, l}} p_{m_{1, h}}\left(1-G_{f}\left(R_{m_{1, l}}^{f_{1, l}}\right)\right) \\
& p_{f_{1, h}}^{m_{1, l}}=p_{f} p_{f_{1, h}} p_{m_{1, l}}\left(1-G_{f}\left(R_{m_{1, l}}^{f_{1, h}}\right)\right) \\
& p_{f_{1, h}}^{m_{1, h}}=p_{f} p_{f_{1, h}} p_{m_{1, h}}\left(1-G_{f}\left(R_{m_{1, h}}^{f_{1, h}}\right)\right) \\
& p_{f_{2, l}}^{m_{1, l}}=p_{f} p_{f_{2, l}} p_{m_{1, l}}\left(1-G_{f}\left(R_{m_{1, l}}^{f_{2, l}}\right)\right) \\
& p_{f_{2, l}}^{m_{1, h}}=p_{f} p_{f_{2, l}} p_{m_{1, h}}\left(1-G_{f}\left(R_{m_{1, l}}^{f_{2, l}}\right)\right) \\
& p_{f_{2, h}}^{m_{1, l}}=p_{f} p_{f_{2, h}} p_{m_{1, l}}\left(1-G_{f}\left(R_{m_{1, l}}^{f_{2, l}}\right)\right) \\
& p_{f_{2, h}}^{m_{1, h}}=p_{f} p_{f_{2, h}} p_{m_{1, l}}\left(1-G_{f}\left(R_{m_{1, h}}^{f_{2, h}}\right)\right)
\end{aligned}
$$

An old man will prefer accepting any proposal from women instead of dying single.

Thus, the probabilities that a young woman and an old woman receives a marriage 
offer from an old man are

$$
\begin{aligned}
& p_{f_{1, l}}^{m_{2, l}}=p_{f} p_{f_{1, l}} p_{m_{2, l}} \\
& p_{f_{1, l}}^{m_{2, h}}=p_{f} p_{f_{1, l}} p_{m_{2, h}} \\
& p_{f_{1, h}}^{m_{2, l}}=p_{f} p_{f_{1, h}} p_{m_{2, l}} \\
& p_{f_{1, h}}^{m_{2, h}}=p_{f} p_{f_{1, h}} p_{m_{2, h}} \\
& p_{f_{2, l}}^{m_{2, l}}=p_{f} p_{f_{2, l}} p_{m_{2, h}} \\
& p_{f_{2, l}}^{m_{2, h}}=p_{f} p_{f_{2, l}} p_{m_{2, h}} \\
& p_{f_{2, l}}^{m_{2, l}}=p_{f} p_{f_{2, l}} p_{m_{2, l}, \text { and }} \\
& p_{f_{2, h}}^{m_{2, h}}=p_{f} p_{f_{2, h}} p_{m_{2, h}}
\end{aligned}
$$

The utility of marriage for old low-educated women is

$$
U_{f_{2, l}}=\left(p_{f_{2, l}}^{m_{1, l}}+p_{f_{2, l}}^{m_{1, h}}+p_{f_{2, l}}^{m_{2, l}}+p_{f_{2, l}}^{m_{2, h}} r\right) \bar{y} .
$$

The utility of marriage for old high-educated women is

$$
U_{f_{2, h}}=V_{f_{2, h}}=\left(p_{f_{2, h}}^{m_{1, l}}+p_{f_{2, h}}^{m_{1, h}}+p_{f_{2, h}}^{m_{2, l}}+p_{f_{2, h}}^{m_{2, h}} r\right) \bar{y} .
$$

\section{A.6 Utility of Marriage for Young Women}

The utilities of marriage for low and high ability young women are

$U_{f_{1, l}}=p_{f_{1, l}}^{m_{1, l}}(1+\beta) k \int_{R_{f_{1}, l}^{m_{1}}}^{1} y d y+p_{f_{1, l}}^{m_{1, h}}(1+\beta) k \int_{R_{f_{1}, l}^{m_{1}}}^{1} y d y+p_{f_{1, l}}^{m_{2, l}} k \int_{R_{f_{1}, l}^{m_{2}}}^{1} y d y+p_{f_{1, l}}^{m_{2, h}} k r \int_{R_{f_{1, l}}^{m_{2}, h}}^{1} y d y$ and 
$U_{f_{1, h}}=p_{f_{1, h}}^{m_{1, l}}(1+\beta) k \int_{R_{f_{1}, h}^{m_{l}}}^{1} y d y+p_{f_{1, h}}^{m_{1, h}}(1+\beta) k \int_{R_{f_{1, h}}^{m_{1}, h}}^{1} y d y+p_{f_{1, h}}^{m_{2, l}} k \int_{R_{f_{1, h}}^{m_{2}, l}}^{1} y d y+p_{f_{1, h}}^{m_{2, h}} k r \int_{R_{f_{1, h}}^{m_{2}, h}}^{1} y d y$

\section{A.7 The Optimization Problem for Young Women}

A young woman maximizes her total discounted utility by choosing an optimal reservation value that she sets for all potential partners, that is,

$$
\begin{aligned}
& V_{f_{1, l}}=\max U_{f_{1, l}}+\left(1-\gamma_{f_{1, l}}\right) \beta U_{f_{2, l}} \\
& \gamma_{f_{1, l}}=p_{f_{1, l}}^{m_{1, l}}\left(1-G_{m}\left(R_{f_{1, l}}^{m_{1, l}}\right)\right)+p_{f_{1, l}}^{m_{1, h}}\left(1-G_{m}\left(R_{f_{1, l}}^{m_{1, h}}\right)\right)+p_{f_{1, l}}^{m_{2, l}}\left(1-G_{m}\left(R_{f_{1, l}}^{m_{2, l}}\right)\right)+p_{f_{1, l}}^{m_{2, h}}\left(1-G_{m}\left(R_{f_{1, l}}^{m_{2, h}}\right)\right) \\
& V_{f_{1, h}}=\max U_{f_{1, h}}+\left(1-\gamma_{f_{1, h}}\right) \beta U_{f_{2, h}} \\
& \gamma_{f_{1, h}}=p_{f_{1, h}}^{m_{1, l}}\left(1-G_{m}\left(R_{f_{1, h}}^{m_{1, l}}\right)\right)+p_{f_{1, h}}^{m_{1, h}}\left(1-G_{m}\left(R_{f_{1, h}}^{m_{1, h}}\right)\right)+p_{f_{1, h}}^{m_{2, l}}\left(1-G_{m}\left(R_{f_{1, h}}^{m_{2, l}}\right)\right)+p_{f_{1, h}}^{m_{2, h}}\left(1-G_{m}\left(R_{f_{1, h}}^{m_{2, h}}\right)\right)
\end{aligned}
$$

where $\gamma_{f_{1, l}}$ and $\gamma_{f_{1, h}}$ are the probabilities that a young low ability woman and young high ability woman get married at age 1 .

\section{A.8 Reaction Functions}

The solutions to the optimization problems are the equilibrium reservation values $R_{f_{i, j}}^{m_{i, j}}$ set by different groups of men and women. They are $R_{m_{1, l}}^{f_{1, l}}, R_{m_{1, l}}^{f_{1, h}}, R_{m_{1, l}}^{f_{2, l}}, R_{m_{1, l}}^{f_{2, h}}$, $R_{m_{1, h}}^{f_{1, l}}, R_{m_{1, h}}^{f_{1, h}}, R_{m_{1, h}}^{f_{2, l}}, R_{m_{1, h}}^{f_{2, h}}, R_{f_{1, l}}^{m_{1, l}}, R_{f_{1, l}}^{m_{1, h}}, R_{f_{1, l}}^{m_{2, l}}, R_{f_{1, l}}^{m_{2, h}}, R_{f_{1, h}}^{m_{1, l}}, R_{f_{1, h}}^{m_{1, h}}, R_{f_{1, h}}^{m_{2, l}}$, and $R_{f_{1, h}}^{m_{2, h}}$. High and low ability young men should set an optimal reservation value so that they are indifferent between marrying when young and remaining single until the second period, that is,

$$
\begin{aligned}
& k(1+\beta) R_{m_{1, l}}^{f_{1, l}}=k(1+\beta) R_{m_{1, l}}^{f_{1, h}}=R_{m_{1, l}}^{f_{2, l}}=r R_{m_{1, l}}^{f_{2, h}}=\beta U_{m_{2, l}} \\
& k(1+\beta) R_{m_{1, h}}^{f_{1, l}}=k(1+\beta) R_{m_{1, h}}^{f_{1, h}}=R_{m_{1, h}}^{f_{2, l}}=r R_{m_{1, h}}^{f_{2, h}}=\beta U_{m_{2, h}}
\end{aligned}
$$

Similarly, for low and high ability young women,

$$
k(1+\beta) R_{f_{1, l}}^{m_{1, l}}=k(1+\beta) R_{f_{1, l}}^{m_{1, h}}=k R_{f_{1, l}}^{m_{2, l}}=k r R_{f_{1, l}}^{m_{2, h}}=\beta U_{f_{2, l}}
$$




$$
k(1+\beta) R_{f_{1, h}}^{m_{1, l}}=k(1+\beta) R_{f_{1, h}}^{m_{1, h}}=k R_{f_{1, h}}^{m_{2, l}}=k r R_{f_{1, h}}^{m_{2, h}}=\beta U_{f_{2, h}}
$$

The resulting reaction functions are as follows:

$$
\begin{aligned}
& R_{m_{1, l}}^{f_{1, l}}=\frac{p_{m} p_{m_{2, l}} \beta\left[p_{f_{1, l}}\left(1-R_{f_{1, l}}^{m_{2, l}}\right) k+p_{f_{1, h}}\left(1-R_{f_{1, h}}^{m_{2, l}}\right) k+p_{f_{2, l}}+p_{f_{2, h}} r\right]}{2 k(1+\beta)} \\
& R_{m_{1, h}}^{f_{1, l}}=\frac{p_{m} p_{m_{2, h}} \beta\left[p_{f_{1, l}}\left(1-R_{f_{1, l}}^{m_{2, h}}\right) \frac{k}{e}+p_{f_{1, h}}\left(1-R_{f_{1, h}}^{m_{2, h}}\right) \frac{k}{e}+p_{f_{2, l}}+p_{f_{2, h}} r\right]}{2 k(1+\beta)} \\
& R_{m_{1, l}}^{f_{1, h}}=\frac{p_{m} p_{m_{2, l}} \beta\left[p_{f_{1, l}}\left(1-R_{f_{1, l}}^{m_{2, l}}\right) k+p_{f_{1, h}}\left(1-R_{f_{1, h}}^{m_{2, l}}\right) k+p_{f_{2, l}}+p_{f_{2, h}} r\right]}{2 k(1+\beta)} \\
& R_{m_{1, h}}^{f_{1, h}}=\frac{p_{m} p_{m_{2, h}} \beta\left[p_{f_{1, l}}\left(1-R_{f_{1, l}}^{m_{2, h}}\right) \frac{k}{e}+p_{f_{1, h}}\left(1-R_{f_{1, h}}^{m_{2, h}}\right) \frac{k}{e}+p_{f_{2, l}}+p_{f_{2, h}} r\right]}{2 k(1+\beta)} \\
& R_{m_{1, l}}^{f_{2, l}}=\frac{p_{m} p_{m_{2, l}} \beta\left[p_{f_{1, l}}\left(1-R_{f_{1, l}}^{m_{2, l}}\right) k+p_{f_{1, h}}\left(1-R_{f_{1, h}}^{m_{2, l}}\right) k+p_{f_{2, l}}+p_{f_{2, h}} r\right]}{2} \\
& R_{m_{1, h}}^{f_{2, l}}=\frac{p_{m} p_{m_{2, h}} \beta\left[p_{f_{1, l}}\left(1-R_{f_{1, l}}^{m_{2, h}}\right) \frac{k}{e}+p_{f_{1, h}}\left(1-R_{f_{1, h}}^{m_{2, h}}\right) \frac{k}{e}+p_{f_{2, l}}+p_{f_{2, h}} r\right]}{2} \\
& R_{m_{1, l}}^{f_{2, h}}=\frac{p_{m} p_{m_{2, l}} \beta\left[p_{f_{1, l}}\left(1-R_{f_{1, l}}^{m_{2, l}}\right) k+p_{f_{1, h}}\left(1-R_{f_{1, h}}^{m_{2, l}}\right) k+p_{f_{2, l}}+p_{f_{2, h}} r\right]}{2 r} \\
& R_{m_{1, h}}^{f_{2, h}}=\frac{p_{m} p_{m_{2, h}} \beta\left[p_{f_{1, l}}\left(1-R_{f_{1, l}}^{m_{2, h}}\right) \frac{k}{e}+p_{f_{1, h}}\left(1-R_{f_{1, h}}^{m_{2, h}}\right) \frac{k}{e}+p_{f_{2, l}}+p_{f_{2, h}} r\right]}{2 r} \\
& R_{f_{1, l}}^{m_{1, l}}=\frac{p_{f} p_{f_{2, l}} \beta\left[p_{m_{1, l}}\left(1-R_{m_{1, l}}^{f_{2, l}}\right)+p_{m_{1, h}}\left(1-R_{m_{1, h}}^{f_{2, l}}\right)+p_{m_{2, l}}+p_{m_{2, h}} r\right]}{2 k(1+\beta)}
\end{aligned}
$$




$$
\begin{aligned}
& R_{f_{1, h}}^{m_{1, l}}=\frac{p_{f} p_{f_{2, h}} \beta\left[p_{m_{1, l}}\left(1-R_{m_{1, l}}^{f_{2, h}}\right)+p_{m_{1, h}}\left(1-R_{m_{1, h}}^{f_{2, h}}\right)+p_{m_{2, l}}+p_{m_{2, h}} r\right]}{2 k(1+\beta)} \\
& R_{f_{1, l}^{m_{1, h}}}^{f_{1, l}}=\frac{p_{f} p_{f_{2, l}} \beta\left[p_{m_{1, l}}\left(1-R_{m_{1, l}}^{f_{2, l}}\right)+p_{m_{1, h}}\left(1-R_{m_{1, h}}^{f_{2, l}}\right)+p_{m_{2, l}}+p_{m_{2, h}} r\right]}{2 k(1+\beta)} \\
& R_{f_{1, h}}^{m_{1, h}}=\frac{p_{f} p_{f_{2, h}} \beta\left[p_{m_{1, l}}\left(1-R_{m_{1, l}}^{f_{2, h}}\right)+p_{m_{1, h}}\left(1-R_{m_{1, h}}^{f_{2, h}}\right)+p_{m_{2, l}}+p_{m_{2, h}} r\right]}{2 k(1+\beta)} \\
& R_{f_{1, l}}^{m_{2, l}}=\frac{p_{f} p_{f_{2, l}} \beta\left[p_{m_{1, l}}\left(1-R_{m_{1, l}}^{f_{2, l}}\right)+p_{m_{1, h}}\left(1-R_{m_{1, h}}^{f_{2, l}}\right)+p_{m_{2, l}}+p_{m_{2, h}} r\right]}{2 k} \\
& R_{f_{1, h}}^{m_{2, l}}=\frac{p_{f} p_{f_{2, h}} \beta\left[p_{m_{1, l}}\left(1-R_{m_{1, l}}^{f_{2, h}}\right)+p_{m_{1, h}}\left(1-R_{m_{1, h}}^{f_{2, h}}\right)+p_{m_{2, l}}+p_{m_{2, h}} r\right]}{2 k} \\
& R_{f_{1, l}^{m_{2, h}}}=\frac{p_{f} p_{f_{2, l}} \beta\left[p_{m_{1, l}}\left(1-R_{m_{1, l}}^{f_{2, l}}\right)+p_{m_{1, h}}\left(1-R_{m_{1, h}}^{f_{2, l}}\right)+p_{m_{2, l}}+p_{m_{2, h}} r\right]}{2 k r} \\
& R_{f_{1, h}}^{m_{2, h}}=\frac{p_{f} p_{f_{2, h}} \beta\left[p_{m_{1, l}}\left(1-R_{m_{1, l}}^{f_{2, h}}\right)+p_{m_{1, h}}\left(1-R_{m_{1, h}}^{f_{2, h}}\right)+p_{m_{2, l}}+p_{m_{2, h}} r\right]}{2 k r}
\end{aligned}
$$

From the above reaction functions, we obtain

$$
\begin{aligned}
& \frac{\partial R_{m_{1, l}}^{f_{1, l}}}{\partial k}<0 \quad \frac{\partial R_{m_{1, l}}^{f_{1, l}}}{\partial k}<0 \quad \frac{\partial R_{m_{1, l}}^{f_{2, l}}}{\partial k}>0 \quad \frac{\partial R_{m_{1, l}}^{f_{2, l}}}{\partial k}>0 \\
& \frac{\partial R_{m_{1, h}}^{f_{1, l}}}{\partial k}<0 \quad \frac{\partial R_{m_{1, h}}^{f_{1, h}}}{\partial k}<0 \quad \frac{\partial R_{m_{1, h}}^{f_{2, l}}}{\partial k}>0 \quad \frac{\partial R_{m_{1, h}}^{f_{2, h}}}{\partial k}>0 \\
& \frac{\partial R_{f_{1, l}}^{m_{1, l}}}{\partial k}<0 \quad \frac{\partial R_{f_{1, l}}^{m_{1, l}}}{\partial k}<0 \quad \frac{\partial R_{f_{1, l}}^{m_{2, l}}}{\partial k}<0 \quad \frac{\partial R_{f_{1, l}}^{m_{2, l}}}{\partial k}<0 \\
& \frac{\partial R_{f_{1, h}}^{m_{1, l}}}{\partial k}<0 \quad \frac{\partial R_{f_{1, h}}^{m_{1, h}}}{\partial k}<0 \quad \frac{\partial R_{f_{1, h}}^{m_{2, l}}}{\partial k}<0 \quad \frac{\partial R_{f_{1, h}}^{m_{2, h}}}{\partial k}<0
\end{aligned}
$$


These imply the more important it is to have children (higher $k$ ), the lower the reservation value a young man will set for a young woman than for an old woman, meaning young men prefer young women to old women; the same applies to old men as well. As for young women, the more important it is to have children, the lower the reservation value they would set in order to marry early.

\section{A.9 The Relationship Between the Demand For Children and the Age and Education Gaps Between Husbands and Wives}

Let $p_{f_{1}}^{m_{2}}$ represent the probability that a young woman marries an old man. Let $p_{m_{1}}^{f_{2}}$ be the probability that a young man marries an old woman.

$$
\begin{aligned}
& p_{f_{1}}^{m_{2}}=p_{m} p_{f}\left[p_{f_{1, l}} p_{m_{2, l}}\left(1-R_{f_{1, l}}^{m_{2, l}}\right)+p_{f_{1, l}} p_{m_{2, h}}\left(1-R_{f_{1, l}}^{m_{2, h}}\right)+p_{f_{1, h}} p_{m_{2, l}}\left(1-R_{f_{1, h}}^{m_{2, l}}\right)+p_{f_{1, h}} p_{m_{2, h}}\left(1-R_{f_{1, h}}^{m_{2, h}}\right)\right] \\
& p_{m_{1}}^{f_{2}}=p_{m} p_{f}\left[p_{f_{2, l}} p_{m_{1, l}}\left(1-R_{m_{1, l}}^{f_{2, l}}\right)+p_{f_{2, h}} p_{m_{1, l}}\left(1-R_{m_{1, l}}^{f_{2, h}}\right)+p_{f_{2, l}} p_{m_{1, h}}\left(1-R_{m_{1, h}}^{f_{2, l}}\right)+p_{f_{2, h}} p_{m_{1, h}}\left(1-R_{m_{1, h}}^{f_{2, h}}\right)\right] \\
& \frac{\partial p_{f_{1}}^{m_{2}}}{\partial k} \propto-\frac{\partial R_{f_{1, l}}^{m_{2, l}}}{\partial k}-\frac{\partial R_{f_{1, l}}^{m_{2, h}}}{\partial k}-\frac{\partial R_{f_{1, h}}^{m_{2, l}}}{\partial k}-\frac{\partial R_{f_{1, h}}^{m_{2, h}}}{\partial k}>0 \\
& \frac{\partial p_{m_{1}}^{f_{2}}}{\partial k} \propto-\frac{\partial R_{m_{1, l}}^{f_{2, l}}}{\partial k}-\frac{\partial R_{m_{1, l}}^{f_{2, h}}}{\partial k}-\frac{\partial R_{m_{1, h}}^{f_{2, l}}}{\partial k}-\frac{\partial R_{m_{1, h}}^{f_{2, h}}}{\partial k}<0 \\
& \partial k
\end{aligned}
$$

$\frac{\partial p_{f_{1}}^{m_{2}}}{\partial k}>0$ implies the greater the demand for children, the greater possibility that a young woman marries an old man; $\frac{\partial p_{m_{1}}^{f_{2}}}{\partial k}<0$ means the greater the demand for children, the lower possibility that an old woman marries a young man. Therefore, the greater demand for children the greater the age gap at first marriage between husbands and wives.

Let $p_{f_{h}}^{m_{l}}$ represent the probability that a high-educated woman marries a man with 
low ability or low-education. Let $p_{m_{h}}^{f_{l}}$ represent the probability that a high-educated man marries a woman either low ability or low-education.

$$
\begin{aligned}
p_{f_{h}}^{m_{l}} & \propto p_{m} p_{f}\left[p_{f_{2, h}} p_{m_{1, l}}\left(1-R_{m_{1, l}}^{f_{2, h}}\right)+p_{f_{2, h}} p_{m_{2, l}}\right] \\
p_{m_{h}}^{f_{l}} & \propto p_{m} p_{f}\left[p_{f_{1, l}} p_{m_{2, h}}\left(1-R_{f_{1, l}}^{m_{2, h}}\right)+p_{f_{2, l}} p_{m_{2, h}}\right] \\
\frac{\partial p_{f_{h}}^{m_{l}}}{\partial k} & <0 \text { because } \frac{\partial R_{m_{1, l}}^{f_{2, h}}}{\partial k}>0 \text { implying the greater demand for children, the }
\end{aligned}
$$

lower the possibility that an old high educated woman marries a man either low ability or low-education, which will decrease the education gap between a husband and wife.

$\frac{\partial p_{m_{h}}^{f_{l}}}{\partial k}>0$ because $\frac{\partial R_{f_{1, l}}^{m_{2, h}}}{\partial k}<0$ meaning the greater demand for children, the greater the possibility that an old high educated man marries a woman either low ability or low-education, which will increase the education gap between a husband and wife. Therefore, the greater demand for children the greater the education gap between a husband and wife. 